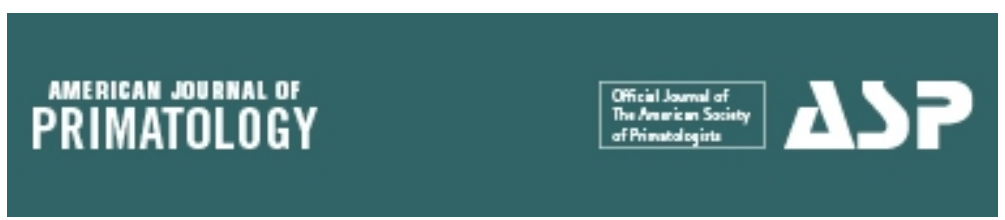

\title{
Environment and Time as Constraints on the Biogeographical Distribution of Gibbons
}

\begin{tabular}{|r|l|}
\hline Journal: & American Journal of Primatology \\
\hline Manuscript ID & AJP-18-0040.R2 \\
\hline Wiley - Manuscript type: & Research Article \\
\hline Author: & n/a \\
\hline $\begin{aligned} \text { Complete List of Authors: } \\
\text { Cunmitted by the } \\
\text { Cheyne, Susan; Borneo Nature Foundation } \\
\text { Lan, Daoying; Guangdong Institute of Applied Biological Resources } \\
\text { Korstjens, Amanda; Bournemouth University, School of Applied Sciences } \\
\text { Lehmann, Julia; Roehampton University, Human and Life Sciences } \\
\text { Cowlishaw, Guy; Institute of Zoology }\end{aligned}$ \\
\hline $\begin{array}{r}\text { Indicate which taxonomic } \\
\text { group was the subject of your } \\
\text { study (select all that apply or } \\
\text { type another option):: }\end{array}$ & Apes (non-human) \\
\hline Keywords: & climate, biogeographic distribution, group size, foraging ecology \\
\hline & \\
\hline
\end{tabular}

\section{SCHOLARONE Manuscripts}




\section{Highlights:}

- Time budgets limit the biogeographic distribution of gibbons and siamang

- Time that has to be allocated to resting seems to be the main constraint

- The limits on group size are not so restrictive as to make monogamy obligatory 


\title{
Environment and Time as Constraints on the Biogeographical
}

Distribution of Gibbons

by

\section{R.I.M. Dunbar}

Department of Experimental Psychology, University of Oxford, Oxford, UK

\section{Susan M. Cheyne}

Borneo Nature Foundation, Palangka Raya, Indonesia \& Oxford Brookes University, Oxford, UK

\author{
Daoying Lan \\ Guangdong Institute of Applied Biological Resources, Guangzhou 510260, China
}

\section{Amanda Korstjens}

Department of Life and Environmental Sciences, Bournemouth University, Poole, UK

\section{Julia Lehmann}

Department of Life Science, University of Roehampton, London, SW15 5JD, UK

\section{G. Cowlishaw}

Institute of Zoology, Zoological Society of London, Regents Park, London NW1 4RY, UK 


\section{Abstract}

We develop a time budget model for the hylobatid family with the aim of assessing the extent to which their contemporary and historical biogeographic distributions might be explained by ecological constraints. The model uses local climate to predict time budgets, and from this the limiting size of social group that animals could manage at a given location. The model predicts maximum group sizes that vary between 3-15 within the taxon's current distribution, indicating that the combination of their dietary and locomotor styles with the kinds of habitats they inhabit radically constrain group size. Beyond the edges of their current distribution, sustainable group size rapidly tends to zero, although if they had been able to bypass some of these areas, they would have found very suitable habitats in southern India and beyond the Wallace Line. While travel time would be a major constraint on group size at larger group sizes, as it is in great apes, the main factor limiting the gibbon's current distribution is the time they need to spend resting that is imposed on them by the environment. The model also indicates that gibbons would not now be able to survive in regions of central and southeastern China where they are known to have occurred within historical times, perhaps because historical climate change following the Little Ice Age of the C18th made these regions uninhabitable for them. Finally, our results indicate that gibbons have the ecological capacity to live in larger groups than they do, making it unlikely that their adoption of monogamy reflects purely ecological constraints.

Key Words: climate, biogeographic distribution, group size, foraging ecology 
52

53

54

55

56

57

58

59

60

61

\section{Highlights:}

- Time budgets limit the biogeographic distribution of gibbons and siamang

- Time that has to be allocated to resting seems to be the main constraint

- The limits on group size are not so restrictive as to make monogamy obligatory 


\section{Introduction}

Inability to satisfy nutritional and other demands within a defined time period (usually a 24-hr physiological cycle: Peters 1983) limits both where a species can live and, in social species, how big their groups can be (Dunbar, Korstjens \& Lehmann 2009). In this respect, time is a central problem for all animals, especially for those that, like primates, are not active 24 hours a day. This insight has led to the development of a series of time budget models designed to understand the role of time in limiting the biogeographical distributions of individual taxa (Dunbar et al. 2009). These models are premised on the fact that behaviour (as the outcome of core physiological processes) is the interface between the environment and the animals' ability to survive (with the latter indexed by the size of group they can maintain as an ecological entity) (see also Marshall, Carter, Rowcliffe \& Cowlishaw 2013). There is little that most animals can do to alter their physiology in response to changes in climate or vegetation, but they can, and do, adjust their behaviour and group sizes in response to changing environmental conditions.

For species like anthropoid primates that (with obvious the exception Aotus) are strictly diurnal due to poor night vision, the time available for satisfying their nutritional requirements is further reduced to the $\sim 12$ hours of tropical daylight. In addition, climate and the species' dietary adaptations may force animals to rest ('enforced rest' sensu Korstjens et al. 2010), thereby further reducing the length of their active day. The climatic component of this relationship reflects the fact that almost all tropical animals are obliged to cease being active and seek shelter during the hottest part of the day when ambient temperatures in open sunlight exceed their thermoneutral zone (Mount 1979; Dàvid-Barrett \& Dunbar 2016); the dietary aspect is mainly a problem for folivores for whom gut fermentation of foliage is incompatible 
with any form of activity because the microbial activity on which it depends is extremely sensitive to the heat generated by physical activity (van Soest 1982).

Intensely social species, like most anthropoid primates, face an additional problem because the functionality of their relationships, as well as the cohesion of their social groups, depends directly on the time they invest in grooming with each other (Lehmann, Korstjens \& Dunbar 2007a; Pollard \& Blumstein 2008; Dunbar \& Shultz 2010; Dunbar \& Lehmann 2013; Sutcliffe, Dunbar, Binder \& Arrow 2012; Dunbar 2018a,b). For both humans and nonhuman primates, an individual's willingness to give coalitionary aid to another depends directly on the amount of time they spend engaged in affiliative interaction (Seyfarth \& Cheney 1984; Dunbar 1980, 2018a,b; Burton-Chellew \& Dunbar 2015). At some point, animals will inevitably run out of time, and this will ultimately limit where they can live. Ecologists tend to see this as a constraint imposed by nutrient availability, but the real constraint is time.

In effect, animals face a three-way optimization problem in which they have to offset the costs of living in social groups (i.e. time investment in social grooming) and the acquisition of nutrients (specified by the ecological determinants of time required for feeding and travel, including the fixed costs of fuelling fertility and lactation) against the benefits of group size as their principal form of predator deterrence. Predation risk will depend on whether the animal is terrestrial or arboreal and on the hunting styles of the local predators (the 'landscape of fear') (Shultz et al. 2004; Shultz \& Finlayson 2010; Tolon et al. 2009; Laundré et al. 2014; Coleman \& Hill 2014; Riginos 2015; Gallagher, Creel, Wilson \& Cooke 2017), but within these constraints the prey species can adjust group size to offset local predation risk.

Focusing on time budgets is not an alternative to the more conventional socioecological approach that typically seeks to identify correlations between, on the one 
hand, group size, population density or behaviour and, on the other hand, climate or forage quality/distribution (Wrangham, Gittleman \& Chapman 1993; Chapman \& Chapman 2000; Snaith \& Chapman 2007; Clutton-Brock \& Janson 2012), or apraoches that explore the efficiency of foraging (e.g. Brockleman et al. 2014). Rather, a focus on time budgets provides a way of looking at the mechanisms that underpin the correlations between environmental variables and population level outcomes (group size and dispersion). Time budgets thus provide insights into the mechanisms involved in these processes, and, in doing so, emphasize a component of that mechanism (namely, time) that is invariably overlooked in most studies.

In addition, a time budget approach allows us to incorporate, directly or indirectly, a range of other factors and causal relationships that bear on animals' ability to survive in particular locations. This is important because biological phenomena are naturally systems-based, with most causal relationships being multivariate and subject to the influence of feedback loops. Failure to incorporate these more complex relationships may result in the over- or underestimation of the importance of particular causal relationships. Time budget models allow us to integrate a range of variables and relationships into a single, coherent model.

The formal structure of time budget models is that of a causal chain. The climate at a given location directly or (via its effect on vegetation quality) indirectly determines the three core elements of the time budget (feeding, moving and minimum or 'enforced' rest time). These in turn determine the limiting size of group that animals can maintain at that location because this depends on how much 'uncommitted' time the animals then have available and the parametric relationship between time invested in relationships and the resulting quality of those relationships (as reflected in group coherence). The maximum possible group size predicted by the 
time budget ultimately determines whether or not the species can live at that location (Dunbar et al. 2009). It is important to appreciate that these models are locationspecific: they make explicit predictions about the behaviour of the animals at a given location, subject to the particular climatic and vegetational conditions pertaining at that location. They are also necessarily genus-specific because they reflect the particular dietary, physiological and body size adaptations that characterize a genus. In this respect, a genus is an ecological species.

Climate variables affect both energy demand (energy animals need to maintain thermoregulation: Mount 1979) and the rate of nutrient intake through the effect climate has on the quality and digestibility of forage (and hence the amount of forage that has to be eaten to extract the required amount of nutrients: van Soest 1982). They also influence both travel time (through their effect on foraging patch size and interpatch distances: Janson \& van Schaik 1988; Chapman \& Chapman 2000) and rest time (when animals are forced to seek shelter because ambient temperatures exceed their thermoneutral zone: Mount 1979; Dàvid-Barrett \& Dunbar 2016). In addition, the feedback loops that are invariably an important component of biological systems can arise when group size, in particular, influences travel time (because larger groups have to travel further if feeding patches are depleted easily - typically, less of a problem for folivores), and this in turn requires more time to be devoted to foraging to replace the energy consumption of the additional travel.

Time budget models consist of a set of simultaneous equations (one for each of the core time budget variables) and thus have the form of a linear programming (or linear optimization) model (Dunbar 2002). The intersection of these equations defines the limit on group size that a species can maintain at a given location. If any of these relationships involve nonlinear components, solving the simultaneous equation set to 
find the maximum group size usually requires numerical rather than analytical methods (Dunbar 1992a; Dunbar et al. 2009). However, if all relationships are linear, analytical methods based on substitution can be used. The set of climatic parameters (the primary drivers, with each as a separate $\mathrm{X}, \mathrm{Z}, \ldots$ axis) and group size (the final output, or Y-axis, variable) define a multidimensional state space. The isosurface defined by points where maximum group size drops below the minimum required for demographic viability and/or predator defence defines the taxon's biogeographic distribution. So long as the predicted maximum group size lies above these minima, the species can survive at those locations, with the magnitude of the difference between the maximum and these minima providing a measure of how much ecological stress the animals are under.

These mechanism-based models are at least as successful as conventional climate (or niche) envelope models at predicting the geographical distributions of the taxa concerned (Willems \& Hill 2009; Korstjens et al. 2010). In addition, they provide insights into which aspects of the animals' ecology are responsible for limiting their distribution (Dunbar et al. 2009). This is because time budget models allow us (a) to determine how much ecological and demographic stress a particular population is under (Dunbar 1992a; Lehmann et al. 2007a) and (b) to specify why the species is unable to occupy particular habitats in ways that directly reflect their physiological adaptations (Dunbar et al. 2009). Neither of these is possible with conventional climate envelope models, which are essentially simple correlational relationships. In addition, because time budget models are driven directly by climate, the models can be used to explore the consequences of past and future climate change for a taxon's biogeographic distribution in a more nuanced way (Lehmann et al. 2010; Kortsjens, Lehmann \& Dunbar 2010; Bettridge \& Dunbar 2012). 
Time budget models have been published for a number of terrestrial (gelada: Dunbar 1992a; baboons: Dunbar 1992b; Bettridge, Lehmann \& Dunbar 2010; African great apes: Lehmann, Korstjens \& Dunbar 2007b, 2008a) and arboreal (spider monkeys: Korstjens, Verhoeckx \& Dunbar 2006; colobins: Korstjens \& Dunbar 2007; vervets: Willems \& Hill 2009; forest guenons: Korstjens, Lehmann \& Dunbar 2018; orangutans: Carne, Semple \& Lehmann 2012) primates, as well as one ungulate (feral goats: Dunbar \& Shi 2013).

Although models have been developed for all three great apes (Lehmann et al. 2007b, 2008a,b; Carne et al. 2012), the small apes (the gibbon family, Hylobatidae) have yet to be considered. The small apes offer a particularly interesting challenge for several reasons. First, for an ape, they occupy an unusually exclusive arboreal terminal branch niche otherwise occupied only by some of the smaller monkeys. Second, they typically live in very small groups (monogamous pairs plus dependent offspring) and this raises questions as to why they have opted for this form of social system. One classic explanation for monogamy in mammals is that females are forced by their ecology to forage on their own in territories that are too large for a male to be able to successfully defend more than one female (Wittenberg \& Tilson 1980; van Schaik \& Dunbar 1990; Komers \& Brotherton 1997; Lukas \& Clutton-Brock 2013); an alternative suggestion is that male parental support allows females to reduce their energy demand, especially in strongly seasonal habitats or where locomotor costs prohibit fat storage (Dunbar 1995a,b; Heldstab, van Schaik \& Isler 2017). Third, they have a relatively limited distribution in southeast Asia, and this limited range begs explanation.

Historically, hylobatids probably evolved as a distinct family in southwest China in the late Miocene, and gradually extended their range down through the 
Malay peninsula into the islands of the Sunda shelf as opportunities provided by changes in climate and sea level allowed (Jablonski \& Chaplin 2009). Turvey, Crees \& Di Fonzo (2015) found that, as late as the 1800s, gibbons were still being recorded in historical documents as widely distributed throughout southern and central China as far north as latitude $\sim 35^{\circ} \mathrm{N}$ (Shanxi, Shaanxi and Shangdong provinces). What explains their disappearance from all but the southwest corner of China (Yunnan and Hainan) remains to be determined, though anthropogenic factors have been suspected (Fan 2017).

In this paper, we have five main aims. The first is to develop a model of hylobatid time budgets in terms of climatic variables. Second, we test the model's validity by using it to predict the taxon's presence and absence in various locations within continental Asia and the islands of the Sunda Shelf and New Guinea. Third, we use the model to determine which time budget variables are most responsible for limiting the taxon's biogeographic distribution. Fourth, we use the model to determine the possible causes of the historical extinction of gibbon populations in China. Finally, we use the results to assess how plausible it is that female spacing best explains hylobatid monogamy.

\section{Methods}

\section{Gibbon data}

A database was compiled from the gibbon literature to provide quantitative data on key demographic, environmental and ecological variables. We identified 77 studies that provide data on at least some of these (see online Dataset S1). Of these, 59 provide data on mean group size, 41 provide data on group density or biomass, and 29 provide data on activity budgets and other behavioural or demographic variables. 
In respect of activity budgets, we identify five mutually exclusive states (feeding, moving or travel, resting, social interaction - mainly social grooming - and singing) which, in this sample, between them account for $\sim 100 \%$ of time.

Inevitably, a number of issues arise when comparing data from different studies. One is that studies vary in the definitions they use for individual behaviour categories; a second is that methods of collecting time budget data vary, both in intensity (e.g. some researchers use group scans, others focal individual sampling) and in coverage (the hours of daylight may not be sampled evenly). While these are certainly issues, past experience developing time budget models suggests that the impact of these methodological issues is at best modest (see Dunbar \& Shi 2013). More importantly, the main consequence of variations in definition and procedure is that they increase the error variance in parameter estimates; increased error variance will simply make it harder to obtain significant results, and will therefore bias the statistical analysis in favour of the null hypothesis (i.e. no relationship). Ultimately, of course, the real test is whether our models predict what we see on the ground despite these methodological flaws. We should be less concerned with standardisation of definitions or methods (though these should always be encouraged) than with whether models based on them correctly predict what we know to be the case.

Where these were given by the original field sources, we also extracted data on a number of ecological and behavioural variables: the percentage of leaf in the diet (\%Leaf), percentage of fruit in the diet (\%Fruit), the density of gibbon groups (groups/ha), gibbon population biomass $\left(\mathrm{kg} / \mathrm{km}^{2}\right)$, mean day journey length $(\mathrm{km})$, mean territory size (ha), density of fig trees (Figdens, indexed as trees/ha) and number of sympatric primate species. Mean day journey length and time spent moving (transformed into hours spent moving per day) were used to calculate travel speed 
$(\mathrm{m} / \mathrm{hr})$. Together, these comprise the set of ecological and covariate variables we will use in model-building.

Data for all sites are provided in online Dataset $S 1$.

\section{Climatic and geophysical data}

Rainfall, altitude and latitude for each study site are those provided by the cited publications, where these are given. Since latitudinal effects should be symmetrical about the equator, we transform all latitudes into absolute latitude. Since individual studies often do not provide all the indices we need, we have sourced all temperature variables (mean annual temperature, TEMP; mean minimum temperature, $\mathrm{TEMP}_{\text {min }}$; mean maximum temperature, $\mathrm{TEMP}_{\text {max }}$; mean daily temperature variation, $\mathrm{TEMP}_{\mathrm{var}}[$ difference between mean minimum and mean maximum temperature]; and the standard deviation of mean monthly temperature, $\mathrm{T}_{\operatorname{moSD}}$ [an index of seasonality]) from either http://www.globalspecies.org/weather_stations/ (which provides climate data for individual wildlife reserves) or http://en.climate-data.org (which provides climate data for civic weather stations). Wherever possible, we gave preference to the first. These climatic variables and the two geographical variables (i.e. latitude and altitude, both of which are determinants of climate) constitute the set of climatic variables that we will use as the main independent variables in model-building.

Previous analyses of weather station data for sub-Saharan Africa have demonstrated that only three climatic variables are needed to predict evapotranspiration (the principal predictor of tropical primary productivity: Rosenzweig 1968; Le Houérou \& Hoste 1977; Lo Seen Chong, Mougin \& Gastellu-Etchegorry 1993). These are mean ambient temperature, total annual rainfall and an index of seasonality (Williamson \& Dunbar 1998; see also Hill 1999). As in our previous 
models for African primates, the standard deviation of mean monthly temperature (TmoSD) is our main index of seasonality. This also allows us to include any effects due to the fact that, in some contexts, certain times of the year when resource availability is poor or climate especially challenging may impose limits on what animals can do (see, for example, Dunbar \& Shi 2013).

Collinearity between the climate variables in the field site dataset is, in general, low and within conventionally acceptable levels, the only exception being that between rainfall and temperature (mainly due to the effect of the cold, dry habitats in southwest China disproportionately influencing what is otherwise a much less clearcut relationship). At best, this relationship explains only $20 \%$ of the variance, and as little as $10 \%$ if the Chinese habitats are excluded.

\section{Model-building procedure}

For the model-building analysis, we excluded time budget data for one study on a heavily logged habitat (Johns 1986) because it had an implausibly low estimate for time spent feeding $(8 \%,>3$ standard deviations below the mean for gibbons, and almost a full SD below the next lowest value) and an implausibly high value for time spent resting $(62 \%, 2.5$ SDs above the overall mean, and a full SD above the next highest value), two studies (West Garo Hills, NE India: Alfred \& Sati 1986, 1990; Ujung Kulon, Indonesia: P. Kappeler 1984a,b) that had very high values for time spent feeding $(>60 \%, 3.1$ and 3.9 SDs above the mean for gibbons, and $>1$ SD above the next nearest value) and unusually low values for resting time, and one (Tanjong Triang: Ellefson 1974) that had an unusually high value for moving (47\%) and low value for rest $(7 \%)$. Such high values for feeding and moving and low values for resting are indicative of gibbons that were not fully habituated. 
In developing any model, we face a choice between detail and generality. It is always possible to build a model that takes every conceivable environmental variable into account, and hence is $100 \%$ accurate in its fit to the data. But in doing so, we inevitably lose generality: in order to make predictions about where the taxon can live, we will need to know much more about the particular environmental parameters of an individual location (e.g. soil type and acidity, inclination and tree composition, as well as all the larger scale variables like rainfall and temperature). Using general climate as the basis for a model allows us, at the expense of some loss of accuracy, to be more general, since relevant climate values can be mapped geographically on a continental scale from climate models, as well as being projected backwards and forwards in time.

For the purposes of building a time budget model, we need to determine taxon-specific equations for just two key variables (feeding and moving time). The other two main components (enforced resting time and social time) use general primate equations given, respectively, by Korstjens et al. (2010) and Lehmann et al. (2007a). For the purposes of the present model, we shall take time devoted to singing as a constant (at the mean observed value of $4.96 \%$ ).

Enforced resting time, as defined by Korstjens et al. (2010), specifies the minimum amount of time that has to be spent resting as a consequence of high ambient temperatures (to avoid thermal overload or excessive heat loss) and for the digestion of leaves (as a function of climatic conditions and the species' dietary physiology). Enforced resting time differs from observed resting time (time spent inactive, as recorded by field observers) in that observed rest time consists of enforced resting time plus uncommitted time ("free rest") (Korstjens et al. 2010).

The time during the day that animals have left over after making their habitat- 
specific allocations to feeding, moving, enforced rest and singing (subject to any feedback loops in the equation set) gives us the amount of time in the day that could be devoted to social interaction (grooming). Because grooming time correlates with group size (Dunbar 1992; Lehman et al. 2007; Dunbar \& Lehmann 2014), we can use this relationship to specify the maximum size of group that the animals could maintain as a coherent social entity at that location. This does not mean the animals have to devote all this time to social interaction: it simply sets the upper limit, and hence the upper limit on social group size.

The social time equation reflects the fact that social grooming is the principal bonding mechanism for primate social groups and increases linearly with group size across primates as a whole (Dunbar 1991; Lehmann et al. 2007; Dunbar \& Lehmann 2014). As such, it represents the time investment in social interaction that is necessary to maintain a group's cohesion through time so as to prevent it disintegrating (Dunbar 1992a, 2012). It is worth noting that this increase in time devoted to grooming with group size does not mean that animals in large groups groom with more individuals. Typically they do not. Rather, as group size increases, animals invest increasingly in the handful of core grooming partners that act as their primary coalition partners within the group because these act as their primary defence against the stresses of living in a group (Kudo \& Dunbar 2001; Dunbar 2012, 2018a).

As in previous models, we first examined all relevant pairwise plots visually to determine whether any factors correlate nonlinearly with the main time budget variables. There were no nonlinear relationships. We then ran backward stepwise linear regression models with the full set of climatic and ecological variables as predictors of each of the two dependent variables (feeding and moving time). The criterion used in selecting the final equation in each case was based on maximising 
the proportion of variance explained, subject to the requirement that the overall equation and all its individual predictor variables were significant.

Because siamang are more than twice as large as other gibbons, siamang feeding time was first corrected to a gibbon-equivalent (i.e. what it would need to do if it was a conventional gibbon) by rescaling it by the ratio of the metabolic body weights of the two taxa (i.e. $5.5^{0.75} / 10.75^{0.75}=0.605$ ). This allows us to use all the data without having to include an additional factor for taxon or body mass. None of the other gibbon species differed significantly in body weight (see Dataset S1).

In extracting these equations from the data, we have ignored the possible influence of phylogeny. As in previous analyses (see Dunbar et al. 2009), we do so principally because almost all of the variables we are concerned with are behavioural rather than anatomical, and are likely to be influenced more heavily by local environmental conditions than by biological inheritance, and thus typically have phylogenetic signals that are close to zero (see Kamilar \& Cooper 2013). In effect, we treat all the hylobatids as belonging to a single ecological species. Inter-population analyses of just this kind have previously been successfully used to explore aspects of the behaviour of gibbons (song function: Cowlishaw 1992, 1996). It is perhaps important to note that we are not seeking to describe the "typical" behaviour of individual gibbon species: rather, our concern is to understand the overall pattern of behavioural flexibility and the effects of climate on biogeography across the whole taxon. For convenience, we adopt the convention of referring to the entire group as hylobatids, and differentiate between siamang and all other gibbon species only on the basis of body size.

We then use this set of equations to determine maximum group size for any given location. Since all the equations in the present case are linear, we use analytical 
methods and solve directly by substitution:

$$
\mathrm{N}_{\mathrm{Max}}=\left(100-\left(\text { Feed }+ \text { Move }+ \text { Rest }_{\text {Enf }}\right)\right) /(\text { grooming equation })
$$

This value is the limiting group size (the maximum ecologically tolerable group size, $\left.N_{\max }\right)$.

In order to exhibit the biogeographical implications of the model in graphable form, we present the main results as 3-dimensional surface plots of maximum group size plotted against (a) absolute latitude and altitude and (b) mean annual rainfall and mean annual temperature. Because a relatively large number of environmental and behavioural variables are involved in the basic model, we need to convert all other variables into functions of just the two variables used for each graph. We do this by using backwards stepwise regression modelling to derive equations for these variables from the data given in online Dataset $S 1$. The resulting equations are given in Table 2.

Of these, latitude, altitude and temperature are well known to be systematically related.

All statistical analyses and graphs were executed in SPSS v.23.

\section{Testing the model}

We test the model by evaluating its ability to predict the presence versus absence of gibbons at a range of locations across the Indian subcontinent, the IndoChina peninsula, Indonesia and the Malay Archipelago, New Guinea and mainland China. For these purposes, we selected a number of locations of known altitude and latitude, which had climatic data available in www.en.climatedata.org. The locations and their climatic and geographical data are given in online Dataset S2. Since these analyses predict where hylobatids can and cannot survive, they also allow us to make inferences about the biogeographic distribution of the taxon. In most cases, we 
413

414

415

416

417

selected major cities for these purposes, since our question is whether or not gibbons could live in the general area, not whether they live at a particular location. These data also allow us to assess whether gibbons could now live in those provinces of China where they were recorded historically by Turvey et al. (2015), and hence determine whether anthropogenic factors or climate change might have been responsible for their extinction. For these purposes we selected one site at random roughly in the center of each of the provinces of modern China.

\section{Results \\ The model}

Table 1 lists the best fit equations for feeding and moving that were generated by the data, as well as the generic primate equations for enforced resting time and social time. The causal relationships involved are summarized in Fig. 1. For reference, alternative "next best" significant equations for feeding and moving time selected by the backwards stepwise regression are given in the Online Supplementary Material (Table S1). Both feeding and moving time increase as habitats become climatically more stressful (low rainfall, low temperature, high altitude, high latitude). Although group size has no effect on feeding time, it has a weak positive effect on moving time even despite the extremely limited variation in hylobatid group size (Fig. 2). Since moving time is the main limiting factor for great apes, and severely limits their biogeographic distribution and group size (Lehmann et al. 2007b, 2008a,b), we ran a separate regression model with just latitude and group size as predictors (Eqn. 2a). It is of significance that, despite an order of magnitude difference in the range of group sizes, the slope coefficient for group size in gibbons is very similar to that for the chimpanzee time budget model (3.08 vs 2.59 , respectively). 
Across the sample of study populations, percentage of fruit in the diet is

439

440

441

442

443

444

445 determined mainly by ambient temperature (Table 2). In contrast, percentage of leaf in diet increases with the level of environmental stress as reflected in rainfall, altitude and temperature variance (Table 2). Although day journey length was not predicted by any of the climatic variables or by fig tree density, territory size is predicted with a very high $\mathrm{r}^{2}$ by a complex of climatic variables (Table 2 ), suggesting that territory sizes get larger as environmental stress increases.

The next step is to use the time budget equations to predict maximum ecologically possible (i.e. limiting) group size, $\max$, for the sampled populations. To do this, we interpolate the time available for social interaction (i.e that remaining after removing the time predicted for feeding, moving and enforced rest at the site, plus the constant for singing) into Eqn. (5). For this analysis, siamang predicted feeding time is rescaled back to siamang body mass by reversing the transformation used to convert their feeding time to gibbon-equivalents.

Fig. 3(a) plots maximum tolerable group size, $N_{\max }$, against observed mean population group size for all the gibbon and siamang populations in our sample. The horizontal line demarcates a group size of 2.96 individuals, representing the minimum group size for demographic viability (i.e. demographic stability defined by a population growth rate of $r=0$ : this requires two surviving offspring over an average gibbon 17-year reproductive lifespan, and would equate to a group with two adults plus $4 / 17=0.12$ births per year, hence an average of $\sim 0.96$ dependent offspring aged $<8$ years at any given time, taking 8 to be the age at dispersal and thus the range of individuals who would be observed in a group). (This value assumes minimal mortality in immature gibbons, which seems broadly to be the case; assuming $50 \%$ mortality up to puberty, a figure typical of terrestrial baboons, would only increase 
463

464

465

466

467

468

469

470

471

472

473

474

475

476

477

478

479

480

481

482

483

484

485

486

487

minimum viable group size to 2 adults $+1.5^{*} 0.96$ living offspring $=3.44$.) The dashed diagonal line marks the line of equivalence $\left(N_{\max }\right.$ is equal to observed mean population size).

Three points may be noted. First, time budget models specify that group sizes should not exceed the predicted maximum size (hence all data points in Fig. 3a should lie above the dashed line). In the present case, $80.5 \%$ of the 41 populations have a predicted maximum group size that is larger than their observed mean group size. This is broadly encouraging as far as model fit is concerned, but suggests that something else is needed to account for the exceptions. Second, no population has $N_{\max }>15$ individuals. This suggests that hylobatids are under rather greater ecological constraint than many other Old and New World monkeys (and African great apes), where limiting group sizes are typically $>20$. Third, notwithstanding this, it is clear that many (but not all) populations could, on ecological grounds, live in much larger groups than they actually do. Such groups would inevitably be multi-female.

One likely reason why some populations might have maximum predicted group sizes below their observed group sizes is the length of the active day. Gibbons are well known to retire early, often several hours before dusk (Raemaekers 1979; Chivers 1984; Palombit 1997; Fei, Zhang, Yuan, Zhang \& Fan 2017), a behaviour that is quite unusual for most primates. As a result, the sampled activity budgets are based on an active day that averages $9.3 \pm 0.89 \mathrm{hrs}$ (range $8.1-10.6, \mathrm{~N}=9$ sites), despite the fact that daylength in tropical habitats is $\sim 12$ hrs. Progessively extending the length of the active day in units of $5 \%$ suggests that an active day that is $15 \%$ ( 84 min) longer than the observed mean would be enough to lift all but the three lowest siamang populations above the demographic viability threshold (Fig. 3b). (This would increase maximum $N_{\max }$ for the other populations only to $\sim 20$.) Unfortunately, data on 
the length of the active day are not available for any of the populations with $N_{\max }<2.96$. However, an extra 84 min would only increase the mean value of day length to $10.7 \mathrm{hrs}$, virtually identical to the longest observed day length in our dataset (10.6 hrs in a siamang population: Dataset S1).

We ran a sensitivity analysis of the model using the alternative equations for feeding and moving time from Table S1. To do this, we altered one of the equations at a time in the original model from Table 1, keeping all the other equations as in the original model. We also ran a model combining the alternative moving time equation with the two most extreme alternative feeding time equations. Predicted maximum group size for the individual populations in the study site database determined using these alternative equations are highly correlated with those determined using the original model (Table S2; Fig. S1). The alternative moving time equation increases the largest maximum group size from $\sim 15$ to $\sim 25$, but does not substantively change any of the results. This suggests that the Table 1 model is quite robust. Similarly, decreasing the slope coefficient for group size in the moving time equation to 2.59 (the value for the chimpanzee model) increases the largest $N_{\max }$ to $\sim 18$, while increasing it to 5.0 decreases $N_{\max }$ to $\sim 9$, but does not alter the broad pattern or the fact that most mean population group sizes are comfortably below $N_{\max }$.

To provide some indication as to how environmental parameters influence hylobatid biogeography, Fig. 4 plots predicted maximum group size as a function of (a) latitude and altitude and (b) rainfall and temperature. To produce these graphs, we have used the equations given in Table 2 to reduce all the climatic variables in the model to the two indices of interest in each case. This can be expected to increase error variance, with a consequential tendency for reversion to the mean, but the results provide us with an indication of how maximum group size is likely to vary across 
habitats. The results suggest that hylobatids do best (i.e. are able to sustain larger groups) in cooler, high altitude, high rainfall habitats at low latitudes (i.e. near the equator). When rainfall is less than $\sim 1500 \mathrm{~mm}$ per annum, or at latitudes above $\sim 20^{\circ}$ (in effect, outside the Tropics), hylobatids are unable to maintain minimally viable groups ( $\mathrm{N} \approx 3$ individuals) unless they are living at altitudes above $\sim 1000 \mathrm{~m}$ (i.e. under cooler conditions) (see also Turvey et al. 2015). This last prediction is confirmed by the fact that the northern Chinese populations are at significantly higher altitudes than all the other hylobatid populations (mean altitudes: $1750.0 \pm 783.8 \mathrm{SD} \mathrm{m}$ vs 401.2 $\pm 409.5 \mathrm{SD} m$ asl, $\mathrm{N}=14$ and 50 respectively; $\left.\mathrm{F}_{1,62}=76.2, \mathrm{p}<0.0001\right)$.

\section{Testing the model}

To explore the model's ability to predict hylobatid biogeography, we used a sample of locations within the current hylobatid biogeographic range in southeast Asia and a sample of locations on the Indian subcontinent, mainland China and the islands of the Malay archipelago outside the current hylobatid range. In addition, we have included one representative site in each of the Chinese provinces where gibbons were recorded as occurring prior to $1800 \mathrm{AD}$ (see Turvey et al. 2015). Note that, for the latter cases, the climate data are current, not historical, values. In each case, we predict maximum group size using current local climate

Fig. 5 plots the mean and range of maximum group size predicted by the model for each of these sites grouped by geographical location. Predicted maximum group sizes average $6.6 \pm 4.0 \mathrm{SD}$ for 18 sites within the current hylobatid range. In contrast, sites in northeast India and Bangladesh to the west of the Brahmaputra (which forms the northwest boundary of the current gibbon range) average $0.3 \pm 0.5 \mathrm{SD}$ ( $\mathrm{N}=7$ sites), as is the case for locations further west in northwest India (mean 
1.6 $\pm 2.2 \mathrm{SD}, \mathrm{N}=7$ sites) (see also Fig. S2). This suggests that, even in the absence of the physical barrier of the Brahmaputra river system, the taxon's ability to expand its range westwards has been limited by substantial tracts of land it would have been unable to cross. Had gibbons been able to bypass these two barriers, they would have found very congenial habitats in the southern parts of the subcontinent (e.g. the Nilgiri Hills and adjacent ranges in the Deccan, and in Sri Lanka), where they would have been able to support groups as large as $8.7 \pm 5.1 \mathrm{SD}(\mathrm{N}=7$ sites $)$. The island habitats across the Wallace Line (specifically, the Celebes and Papua New Guinea) provide equally gibbon-friendly habitats (mean group size $10.3 \pm 1.1 \mathrm{SD}, \mathrm{N}=2$ sites), but it seems that, as with most other primates (Brandon-Jones 1998), the gibbons were never able to traverse this major sea barrier. Increasing the length of the available day by $15 \%$ (as in Fig. 3b) does not change the overall pattern, or make regions such as northern India or central China any more habitable for gibbons.

More puzzling, however, is the fact that central and east Java (including nearby islands like Bali) provide very suitable habitats (mean $N_{\max } 10.4 \pm 1.2 \mathrm{SD}, \mathrm{N}=7$ sites) yet have no gibbon populations. Climatically at least, these habitats seem to be at least as suitable as those in west Java where gibbons do occur (mean $N_{\max }$ 10.2 $\pm 1.9 \mathrm{SD}, \mathrm{N}=7$ sites). In contrast, gibbons would now find it impossible to survive in either the central and southeastern provinces of China where they were recorded as living prior to $1800 \mathrm{AD}$ (mean $0.0 \pm 0.0 \mathrm{SD}, \mathrm{N}=14$ sites) or, perhaps less surprisingly, the provinces of northern China where they did not occur historically (mean 1.3 $\pm 3.6 \mathrm{SD}, \mathrm{N}=7$ ). This contrasts with locations in southwest China (Yunnan province and Hainan Island) that currently do support gibbon populations, for which the model predicts viable group sizes (mean $N_{\max }=4.3 \pm 1.7 \mathrm{SD}, \mathrm{N}=3$ sites). 


\section{What limits hylobatid distribution?}

An important feature of time budget models is that they allow us to determine which aspect of the animals' biology is the principal constraint on their ability to occupy habitats, and hence what actually limits their biogeographic distribution. In turn, this tells us something about the taxon's risk of extinction under climate change. To explore this, we plotted the predicted time required for feeding, moving and enforced rest for the Dataset $S 2$ locations (Fig. 6). Neither feeding nor moving differ consistently between regions where hylobatids are present vs not present, suggesting that neither of these is a major constraint (except, in the limit, the effect of group size on moving time at much larger group sizes); in contrast, resting is significantly higher in regions where they are absent and seems to account for the fact that they do not have sufficient time for social interaction to maintain groups of any significant size.

It thus seems that the main problem lies in the extent to which climatic variables oblige them to rest. This is confirmed by an analysis of observed versus predicted time budget allocations in the sample study sites. Fig. 7a plots the ratio of observed feeding and resting time divided by the values predicted by the model equations in Table 1 for those populations in the field study dataset (Dataset S1) for whom predicted maximum ecologically tolerable group size is either less than or greater than 5 (the upper limit for observed mean population group size). For these purposes, predicted rest is enforced rest time, while observed rest is total rest time. Feeding time is close to that predicted in both cases, as should be the case. In contrast, observed rest time is significantly less than the minimum predicted ('enforced' rest) in populations where Nmax is less than 5 , whereas populations where Nmax exceeds 5 typically have surplus rest time capacity. The strength of this effect is clear from Fig. $7 \mathrm{~b}$ which plots the difference between observed and predicted rest against the 
difference between observed group size versus predicted Nmax for the populations. The correlation is highly significant $(\mathrm{r}=-0.847, \mathrm{p}<0.0001)$.

\section{Discussion}

The time budget model for hylobatids that we develop here is broadly similar in form to the models developed for 10 other primate genera. It works well for contemporary populations, predicting presence in most cases where gibbons occur and absence where they do not (Fig. 5). In other cases, it is clear that physical barriers (e.g. habitat conditions in northeast India or the Wallace Line to the southeast) have prevented gibbons expanding into habitats where they could do well. It is important to remember that time budget models predict the largest groups that a taxon can maintain at a given site (in effect, the carrying capacity), not necessarily the actual size of group. They simply set the upper limit defined by local environmental conditions. Since, for primates in general, fertility is almost always adversely affected by increasing group size (van Schaik 1982; Dunbar 2018a; Dunbar, MacCarron \& Shultz 2018a), animals will generally try to minimize group size in any given location to the extent that this is compatible with the constraints imposed by the local predation risk (Dunbar et al. 2009; Dunbar et al. 2018a).

The fact that hylobatids commonly live in groups that are smaller than those allowed by the local ecology has two important implications. First, it implies that, while the model certainly tells us that gibbons are under greater ecological constraint than most Old World monkeys and African great apes, the level of ecological stress is not sufficiently high to force them to live in groups as small as those they actually live in. While it is true that some populations have time budgets with little or no spare capacity, many do not (Fig. 7). This conclusion is supported by the fact that, unlike 
613

614

615

616

617

618

619

620

621

622

623

624

625

626

627

628

629

630

631

632

633

634

635

636

637

most other monkeys and apes, hylobatids commonly go to their night rest midafternoon (Raemaekers 1979; Srikosamatara 1984; Palombit 1999; Fei et al. 2017), implying that they are not under significant time pressure. Second, it suggests that predation risk must be low for hylobatids; group size evidently does not provide gibbons with a significant anti-predator advantage, so they can afford to minimize group size in order to maximize fertility (see Dunbar et al. 2009; Bettridge, Lehmann \& Dunbar 2010; Dunbar, MacCarron \& Robertson 2018b). Indeed, in comparison to almost all other primates, cases of predation are conspicuous by their absence from the gibbon literature (Reichard 2003).

This calls into question the claim that gibbons are monogamous because females are forced by their ecology to forage on their own rather than in groups (van Schaik \& van Hooff 1983; Rutberg 1985; Komers \& Brothertpn 1997; Brotherton \& Komers 2003; Lukas \& Clutton-Brock 2013). Contrary to this claim, it seems that most populations could in fact maintain larger groups (range 5-12 animals), especially in the more southerly parts of the Malay archipelago. Groups of this size could easily include 2-4 reproductive females (across all primates, reproductive females form a very consistent $30-35 \%$ of the group: Dunbar et al. 2018a,b). Even if females lived alone, it would be possible to have more of them within a gibbon group's current territory, and males would have access to more than one reproductive female if they pursued a roving male strategy (much as orang utan males do) (see also van Schaik \& Dunbar 1990; Bartlett 2009). This implies, as suggested by van Schaik \& Dunbar (1990) and Opie, Atkinson, Dunbar \& Shultz (2014), that monogamy must have evolved in response to factors other than ecological constraints.

One of the main benefits of the time budget model approach is that it provides insights into the behavioural and physiological constraints that limit a taxon's ability 
638

639

640

641

642

643

644

645

646

647

648

649

650

651

652

653

654

655

656

657

658

659

660

661

662

to successfully occupy different kinds of habitats. As with previous primate time budget models, feeding time is strongly influenced by predictors of habitat quality: in the hylobatid case, the main determinants of feeding time (rainfall, altitude and latitude, with the latter two both being core predictors of temperature) are all variables that influence both tree species composition and the nutritional quality of vegetation (see also Marshall \& Leighton 2006). As food quality falls, animals will need to spend longer feeding to meet their nutritional requirements.

In contrast, time spent moving remains largely independent of the climatic variables, being affected only by absolute latitude and group size. Models for African genera have also noted that moving time tends to be independent of environmental variables and is often close to being a constant (Dunbar et al. 2009), mainly because, in order to save time for other more pressing activities, animals respond by increasing travel speed rather than increasing travel time when they need to travel further (baboons: Dunbar 1992a). There is some suggestion that gibbons also do this: travel speed increases as climatic conditions deteriorate (i.e. when temperatures are high and latitude is low, although the effect is weak and not significant (Fig. S3). However, since there is inevitably a limit on the speed at which animals can travel, at some point animals simply have to devote more time to moving. The substantive issue for day journey length (and hence moving time) is, at least for non-folivores (Snaith \& Chapman 2007), group size: the area that has to be covered to allow every animal in the group to meet its nutritional requirements is inevitably a linear function of the number of animals in the group, forcing the group to travel further each day (Dunbar et al. 2009). The great apes are especially susceptible to the effects of group size on moving time, and it is this that is mainly responsible for chimpanzees' fission-fusion form of sociality (Lehmann et al. 2007b, 2008a,b). It is significant that, despite the 
663

664

665

666

667

668

669

670

671

672

673

674

675

676

677

678

679

680

681

682

683

684

685

686

687

very limited variance in the size of their groups, the group size slope parameter for the gibbons is similar to that for chimpanzees. For groups as small as those found in gibbons, the impact of this effect will, of course, be modest; but it does mean that when groups are larger than $\sim 10$ the impact will rapidly becomes prohibitive (as is the case for African great apes: Lehmann et al. 2007b [Fig. 7]).

However, it seems to be enforced resting time that is the main constraint for hylobatids (Figs. 6 and 7). Since this is mainly affected by ambient temperature, it might explain why social groups get larger in northern populations irrespective of species (Fig. 8). Ultimately, however, the northern extension of hylobatids is constrained by the fact that feeding and moving time are also positive functions of latitude (and hence, in effect, declining temperatures). A comparison of the slope parameters for latitude in Tables 1 and 2 indicates that the additive effects of the latitude coefficients for feeding and moving time increase at a combined rate that is $\sim 4$ times the savings in terms of the slope for enforced rest $(0.363+0.462=0.825 \mathrm{vs}$ $1.33 * 0.158=0.210$ ), so that time budgets become progressively squeezed as animals occupy increasingly high latitude habitats. At the latitude of Mt Wuliang in Yunnan Province, latitude has added a net 15 percentage points to the time budget.

There is a widespread perception that Nomascus populations live in larger groups than all other hylobatids, hence the fact that they have polygamous groups. Up to a point, this is true; however, this is not true for all Nomascus populations (Fig. 8). Moreover, Hoolock populations also have large groups at high latitudes without these being polygamous. Mean population group size is in fact a cubic function of absolute latitude (Fig. 8). Group size does increase steadily up to around $20^{\circ} \mathrm{N}$ (roughly the latitude of Chaing Mai in northern Thailand), but then it levels off only to drop precipitately after latitude $25^{\circ} \mathrm{N}$ (roughly the latitude of Mt Wuliang in southwestern 
China). This decline at very high latitudes is suggestive of populations living at the limits of their range, and indeed mean group size at these highest latitude populations is only just above the minimum for demographic viability.

It is evident from Fig. 3(b) that siamang incur an additional cost due to the fact that their larger body size imposes a higher feeding time demand. A convincing explanation for their larger body size remains elusive, especially given the fact that their range overlaps that of other gibbons and the two taxa are often sympatric. As a result, however, they are often under significant time budget pressure. There is some evidence to suggest that they make time budgeting adjustments that might be sufficient to reduce this pressure: for the limited sample available, it seems that siamang devote less time each day to both singing and social interaction than gibbons do, and they have a longer active day (Table 3). For this limited sample, the net gain for siamang is equivalent to increasing the length of the active day by $\sim 17 \%$ (the combined effect of a longer active day adjusted for less time spent socialising and singing) while only having to increase the actual length of the active day by $\sim 10 \%$. That is sufficient to just lift the lower siamang populations in Fig. 3(b) into the minimum viability zone. Nonetheless, siamang populations are clearly under more ecological pressure than is typical of the other gibbons (Fig. 3).

Gibbons share with the great apes a dietary physiology specialized for frugivory; indeed, their feeding time equation is very similar to that of the gorilla, though their size precludes their being able to survive on low quality folivorous fallback foods in the way gorillas can. Although the larger-bodied siamang exhibit some capacity in this direction (Raemaekers 1979; Palombit 1995), their ability to resort to a heavily folivorous diet is likely to be considerably less than the gorilla's simply because of their smaller body size. Mast years aside, fruits invariably have a 
more patchy distribution than leaf, and the travel demands imposed by this may be part of the problem that affects gibbon time budgets, and hence limits group sizes.

Gibbon ecology appears to be quite tightly defined: their geographical range is surprisingly limited. They are currently confined to the Indochina peninsula (bridging out into southwest China) and the associated islands of the Malay archipelago (Sumatra, Java and Borneo). They appear to have been prevented from extending southeastwards by the Wallace Line (despite the fact that the islands beyond would be perfectly habitable for them: Fig. 5), while their capacity to encroach into the Indian subcontinent has been limited by the climate west of the Brahmaputra (Fig. 6). Nonetheless, within their core distribution they seem to be under much less ecological constraint than we might have anticipated given the female-dispersion explanation for their adoption of a monogamous mating/social system.

Historically, gibbons are known to have occurred at much higher latitudes in China than they do now. The model suggests that current climate in these areas makes these habitats completely unsuitable for gibbons. Although the historical extinction of these northern populations has been attributed to anthropogenic factors (Fan 2017), in fact these habitats would not support gibbons now even if there were no humans living there. There are only three plausible explanations for the disappearance of these populations. One is that the populations in question had evolved novel adaptations to these environments, such that the slope parameters on their feeding and/or moving equations were radically different from those for gibbons from further south, but that humans caused their extermination nonetheless. However, to suggest that these northern gibbons were doing something completely different to all other New and Old World anthropoid primates as well as other gibbons implies that they could not have been conventional primates, and that should be, at best, an explanation of last resort. 
A second possibility is that humans had released animals in these areas in order to have them as exotics (something that humans seem to be especially prone to do), even though the habitats were not really suitable for them; as a result, the populations went extinct once they were no longer being replenished (a situation not too dissimilar to that of Macaca sylvanus on Gibraltar). This is a possibility, but the fact that gibbons seem to be unable to survive there at all would imply the need for constant replenishment, and this seems unlikely over such a wide area and such a long time period. The third option is that the climate has changed in the past 300 years in ways that would have led to the inevitable extinction of these populations (with or without the assistance of humans).

A potential culprit in the latter respect is the Little Ice Age of 1645-1715, which resulted in average world temperatures falling by $\sim 1^{\circ} \mathrm{C}$. In China, this resulted in a significant increase in climatic seasonality. The cultivation of Mediterranean-type citrus crops was abandoned in Jiangxi Province (one of the provinces that historically harboured gibbons: Turvey et al. 2015) after the 1750s, despite their having been cultivated there for many centuries (Reiter 2000). Guangdong (another of the provinces where gibbons have been documented) experienced a particularly cold, dry spell, accompanied by an unusually high frequency of typhoon strikes, after the Little Ice Age (Liu, Shen \& Louie 2001). Ameca y Juárez, Mace, Cowlishaw, Cornforth \& Pettorelli (2013) have shown, for mammals as a whole and primates in particular, that high frequencies of cyclones and droughts correlate with elevated extinction risk (indexed by the number of taxa classified as "threatened"), with the southeast corner of China being especially prone to this effect. Turvey et al. (2015) noted that there was increasing fragmentation of these populations from 1700 onwards (with a marked upturn in fragmentation from around 1900), with a 50-100 year lag to last reported 
occurrence. This is indicative of populations struggling to survive.

A comparison of the distribution of climatic variables in southwest China (where gibbons live now) and central and southeast China (where they lived historically) suggests that the only climate variables in which these two regions differ significantly are $\mathrm{TEMP}_{\mathrm{moSD}}$ (standard deviation of mean monthly temperature across the year, an index of seasonality) and annual rainfall (Table 4). (We do not consider latitude or altitude since these cannot have changed historically.) This may well reflect shifting patterns in the latitudinal distribution of the monsoon circulation, allowing an extension of a more seasonal monsoon climate further into mainland China after the Little Ice Age. A 65\% increase in rainfall and a dramatic reduction in seasonality would be required to allow gibbons to survive in the southeastern provinces as well as they currently do in the southwest.

The bottom line seems to be that even if anthropogenic factors have been important in the final demise of these populations (as both Turvey et al. 2015 and Fan 2017 have suggested), these populations' sensitivity to anthropogenic factors is likely to have been exacerbated by environmental effects on the animals' increasing inability to cope as climate changed. The results in Fig. 4, for example, imply that, historically, declining populations at high latitudes are likely to have become locked into mountain-top retreats as climate deteriorated, leading to small, isolated pockets that are inevitably more vulnerable to extinction in the face of environmental shocks (Dunbar 1998; Cowlishaw \& Dunbar 2000).

One final puzzle is the fact that gibbons are not found east of the Dieng Mountains in central Java. Kappeler $(1984 a, b)$ attributed this to the kinds of forests found in the eastern half of the island, which tend to be more deciduous. Fossil gibbons have been recorded at Trinil, central Java (in the Lower/Middle Pleistocene 
788 deposits that produced the hominins: Ingicco, Vos \& Hoffman 2014) and at the 789 Ngandong and Gunung Dawung hominin sites in east Java (Storm \& Vos 2006) (see 790 also Jablonski \& Chapin 2009), so this area clearly did once support gibbon 791 populations. The fact that west Java was one of the refugia for gibbons during the dry 792 phases of the late Pleistocene Ice Ages (Brandon-Jones 1998) makes this all the more 793 puzzling. It may be that anthropogenic factors resulted in their demise, although these 794 are unlikely to have kicked in until historical times.

\section{Acknowledgements}

798 The authors declare no conflicts of interest. This paper is based entirely on published 799 data and no ethical issues arise from it. We thank the referees for some helpful 800 suggestions. 
802

803

804

805

806

807

808

809

810

811

812

813

814

815

816

817

818

819

820

821

822

823

824

825

826

\section{REFERENCES}

Ameca y Juárez, E.I., Mace, G.M., Cowlishaw, G., Cornforth, W.A. \& Pettorelli, N. (2013). Assessing exposure to extreme climatic events for terrestrial mammals. Conservation Letters, 6, 145-153.

Alfred, J.R.B. \& Sati, J.P. (1986). The gibbon with special reference to H. hoolock. In Majupuria, T. C. (Ed.), Wildlife wealth of India: Resources and management, pp. 384-390. Bangkok: Technical Press Service.

Alfred, J.R.B. \& Sati, J.P. (1990). Survey and census of the hoolock gibbon in west Garo Hills, Northeast India. Primates, 31, 299-306.

Bartlett, T.Q. (2009). Seasonal home range use and defendability in white-handed gibbons (Hylobates lar) in Khao Yai National Park, Thailand. In S. Lappan \& D.J. Whittaker (Eds.), The gibbons, pp. 265-275. New York: Springer.

Bettridge, C. \& Dunbar, R.I.M. (2012). Modelling the biogeography of fossil baboons. International Journal of Primatology, 33, 1278-1308.

Bettridge, C., Lehmann, J. \& Dunbar, R. (2010). Trade-offs between time, predation risk and life history, and their implications for biogeography: a systems modelling approach with a primate case study. Ecological Modelling, 221, 777-790.

Brandon-Jones, D. (1998). Pre-glacial Bornean primate impoverishment and Wallace's Line. In Hall, R. \& Holloway, J.D. (Eds.), Biogeography and geological evolution, pp. 393-404. Leiden: Backhuys.

Brockelman, W.Y., Nathalang, A., Greenberg, D.B. \& Suwanvecho, U. (2014). Evolution of small-group territoriality in gibbons. In J. Yamagiwa \& $\underline{\mathrm{L}}$.

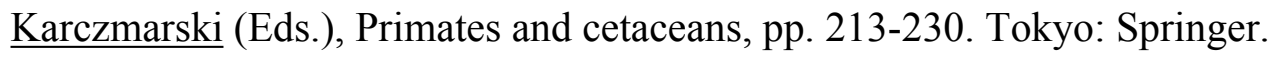


Brotherton, P.N.M. \& Komers, P.E. (2003). Mate guarding and the evolution of social monogamy in mammals. In U.H. Reichard \& C. Boesch (Eds.), Monogamy: mating strategies and partnerships in birds, humans and other mammals, pp. 42-58. Cambridge: Cambridge University Press.

Bryant, J.V., Olson, V.A., Chatterjee, H.J. \& Turvey, S.T. (2015). Identifying environmental versus phylogenetic correlates of behavioural ecology in gibbons: implications for conservation management of the world's rarest ape. BMC Evolutionary Biology, 15, 171.

Burton-Chellew, M. \& Dunbar, R.I.M. (2015). Hamilton's Rule predicts anticipated social support in humans. Behavioral Ecology, 26, 130-137.

Carne, C., Semple, S. \& Lehmann, J. (2012). The effects of climate change on orangutans: a time budget model. Climate Models. www.InTechOpen.com. doi: $10.5772 / 3324$

Chapman, C., \& Chapman, L. (2000). Determinants of group size in primates: the importance of travel costs. In S. Boinski \& P. A. Garber (Eds.), On the move: how and why animals travel in groups (pp. 24-42). Chicago: University of Chicago Press.

Chivers, D.J. (1984). Feeding and ranging in gibbons: a summary. In Preuschoft, H.H., Chivers, D.J., Brockelman, W.Y. \& Creel, N. (Eds.), The lesser apes, pp. 267-281. Edinburgh: Edinburgh University Press.

Clutton-Brock, T. \& Janson, C. (2012). Primate socioecology at the crossroads: past, present, and future. Evolutionary Anthropology, 21, 136-150.

Coleman, B.T. \& Hill, R.A. (2014). Living in a landscape of fear: the impact of predation, resource availability and habitat structure on primate range use. Animal Behaviour, 88, 165-173. 
852 Cowlishaw, G. (1992). Song function in gibbons. Behaviour, 121, 131-153.

853 Cowlishaw, G. (1996). Sexual selection and information content in gibbon song $854 \quad$ bouts. Ethology, 102, 272-284.

855 Cowlishaw, G. \& Dunbar, R.I.M. (2000). Primate conservation biology. Chicago: $856 \quad$ Chicago University Press.

857 Dàvid-Barrett, T. \& Dunbar, R.I.M. (2016). Bipedality and hair loss in human 858 evolution revisited: the impact of altitude and activity scheduling. Journal of $859 \quad$ Human Evolution, 94, 72-82.

860 Dunbar, R.I.M. (1980). Determinants and evolutionary consequences of dominance 861 among female gelada baboons. Behavioural Ecology and Sociobiology, 7, 253-265.

862 Dunbar, R.I.M. (1992a). Time: a hidden constraint on the behavioural ecology of $863 \quad$ baboons. Behavioural Ecology and Sociobiology, 31, 35-49.

864 Dunbar, R.I.M. (1992b). A model of the gelada socioecological system. Primates, 33, 865 69-84.

Dunbar, R.I.M. (1995a). The mating system of Callitrichid primates. I. Conditions for the coevolution of pairbonding and twinning. Animal Behaviour 50: 10571070.

Dunbar, R.I.M. (1995b) The mating system of Callitrichid primates. II. The impact of helpers. Animal Behaviour 50: 1071-1089.

Dunbar, R.I.M. (1998). Impact of global warming on the distribution and survival of the gelada baboon: a modelling approach. Global Change Biology, 4, 293-304. 
Dunbar, R.I.M. (2018a). Social structure as a strategy to mitigate the costs of groupliving: a comparison of gelada and guereza monkeys. Animal Behaviour, 136, $53-64$.

Dunbar, R.I.M. (2018b). The anatomy of friendship. Trends in Cognitive Science, 22, $32-51$.

Dunbar, R.I.M. \& Lehmann, J. (2013). Grooming and social cohesion in primates: a comment on Grueter et al. Evolution and Human Behaviour, 34, 453-455.

Dunbar, R.I.M. \& Shi, J. (2013). Time as a constraint on the distribution of feral goats at high latitudes. Oikos, 122, 403-410.

Dunbar, R.I.M. \& Shultz, S. (2010). Bondedness and sociality. Behaviour, 147, 775-803.

Dunbar, R., Korstjens, A. \& Lehmann, J. (2009). Time as an ecological constraint. Biological Reviews, 84, 413-429.

Dunbar, R., MacCarron, P. \& Shultz, S. (2018a). Primate social group sizes exhibit a regular scaling pattern with natural attractors. Biology Letters, 14, 20170490.

Dunbar, R.I.M., MacCarron, P. \& Robertson, C. (2018b). Tradeoff between fertility and predation risk drives a geometric sequence in the pattern of group sizes in baboons. Biology Letters, 14, 20170700

Ellefson, J.O. (1974). A natural history of the white-handed gibbon in the Malayan Penninsula. In Rumbaugh, D.M. (Eds.), Gibbon and siamang, Vol. 3, pp. 1136. Basel: Karger.

Fan, P. (2017). The past, present, and future of gibbons in China. Biological Conservation, 210, 29-39..

Fei, H.-L., Zhang, D., Yuan, S.D., Zhang, L. \& Fan, P-F. (2017). Antipredation sleeping behavior of skywalker hoolock gibbons (Hoolock tianxing) in Mt. Gaoligong, Yunnan, China. International Journal of Primatology, 38, 629- 
900

901

902

903

904

905

906

907

908

909

910

911

912

913

914

915

916

917

918

919

920

921

922

923

924

641.

Gallagher, A.J., Creel, S., Wilson, R.P. \& Cooke, S.J. (2017). Energy landscapes and the landscape of fear. Trends in Ecology \& Evolution, 32, 88-96.

Heldstab, S.A., Schaik, C.P. \& Isler, K. (2017). Getting fat or getting help? How female mammals cope with energetic constraints on reproduction. Frontiers in Zoology, 14, 29.

Hill, R.A., Lycett, J.E. \& Dunbar, R.I.M. (2000). Ecological determinants of birth intervals in baboons. Behavioral Ecology, 11, 560-564.

Hill, R.A (1999). Ecological and demographic determinants of time budgets in baboons: implications for cross-populational models of baboon socioecology. PhD thesis, University of Liverpool.

Ingicco, T., de Vos, J. \& Huffman, O.F. (2014). The oldest gibbon fossil (Hylobatidae) from insular Southeast Asia: evidence from Trinil (East Java, Indonesia), Lower/Middle Pleistocene. PLoS ONE, 9, e99531.

Jablonski, N.G. \& Chaplin, G. (2009). The fossil record of gibbons. In S. Lapan \& D. Whittaker (Eds.), The gibbons, pp. 111-130. New York: Springer.

Janson, C. H., \& van Schaik, C. P. (1988). Recognizing the many faces of primate food competition: methods. Behaviour, 105, 165-186.

Johns, A. (1986). Effects of selective logging on the behavioural ecology of west Malaysian primates. Ecology, 67, 684-694.

Kamilar, J.M. \& Cooper, N. (2013). Phylogenetic signal in primate behaviour, ecology and life history. Philosophical Transactions of the Royal Society, London, 368B, 20120341.

Kappler, M. (1984a). The gibbon in Java. In Preuschoft, H.H., Chivers, D.J., Brockelman, W.Y. \& Creel, N. (Eds.), The lesser apes, pp. 19-31. Edinburgh: 
Edinburgh University Press.

Kappeler, M. (1984b). Diet and feeding behaviour of the moloch gibbon. In Preuschoft, H.H., Chivers, D.J., Brockelman, W.Y. \& Creel, N. (Eds.), The lesser pes, pp. 228-241. Edinburgh: Edinburgh University Press.

Komers, P.E. \& Brotherton, P.N.M. (1997). Female space use is the best predictor of monogamy in mammals. Proceedings of the Royal Society, London, 264B, $1261-1270$.

Korstjens, A. \& Dunbar, R. (2007). Time constraints limit group sizes and distribution in red and black-and-white colobus monkeys. International Journal of Primatology, 28, 551-575.

Korstjens, A., Lehmann, J. \& Dunbar, R. (2010). Resting time as an ecological constraint on primate biogeography. Animal Behaviour, 79, 361-374.

Korstjens, A.H., Lehmann, J. \& Dunbar, R.I.M. (2018). Time constraints do not limit group size in arboreal guenons but do explain community size and distribution patterns. International Journal of Primatology (in press).

Korstjens, A., Verhoeckx, I. \& Dunbar, R. (2006). Time as a constraint on group size in spider monkey. Behavioural Ecology and Sociobiology, 60, 683-694.

Kudo, H. \& Dunbar, R.I.M. (2001). Neocortex size and social network size in primates. Animal Behaviour, 62, 711-722.

Laundré, J.W., Hernández, L., Medina, P.L., Campanella, A., López-Portillo, J., González-Romero, A., Grajales-Tam, K.M., Burke, A.M., Gronemeyer, P. \& Browning, D.M. (2014). The landscape of fear: the missing link to understand top-down and bottom-up controls of prey abundance? Ecology, 95, 1141-1152.

Lehmann, J., Korstjens, A. \& Dunbar, R.I.M. (2007a). Group size, grooming and social cohesion in primates. Animal Behaviour, 74, 1617-1629. 
Lehmann, J., Korstjens, A. \& Dunbar, R.I.M. (2007b). Fission-fusion social systems 951 as a strategy for coping with ecological constraints: a primate case. Evolutionary Ecology, 21, 613-634.

Lehmann., J., Korstjens, A. \& Dunbar, R.I.M. (2008a). Time management in great apes: implications for gorilla biogeography. Evolutionary Ecology Research, 10, $515-536$.

Lehmann, J., Korstjens, A. \& Dunbar, R.I.M. (2008b). Time and distribution: a model of ape biogeography. Ethology, Ecology and Evolution, 20, 337-359.

Lehmann, J., Korstjens, A. \& Dunbar, R.I.M. (2010). Apes in a changing world - the effects of global warming on the behaviour and distribution of African apes. Journal of Biogeography, 37, 2217-2231.

Le Houérou, H.N. \& Hoste, C.H. (1977). Rangeland production and annual rainfall relations in the Mediterranean Basin and in the African Sahelo-Sudanian zone. Journal of Range Management, 30, 181-189.

Liu, K. Shen, C. \& Louie, K. (2001). A 1,000-year history of typhoon landfalls in Guangdong, Southern China, reconstructed from Chinese historical documentary records. Annals of the Association of American Geographers, 91, $453-464$.

Lo Seen Chong, D., Mougin, E. \& Gastellu-Etchegorry, J.P. (1993). Relating the global vegetation index to net primary productivity and actual evapotranspiration over Africa. International Journal of Remote Sensing, 14, $1517-1546$.

Lukas, D. \& Clutton-Brock, T.H. (2013). The evolution of social monogamy in mammals. Science, 341, 526-530.

Marshall, A.J. \& Leighton, M. (2006). How does food availability limit the population 
density of white-bearded gibbons? In Hohmann, G., Robbins, M.M. \& Boesch, C. (Eds.), Feeding ecology in apes and other primates, pp. 311-333. Cambridge: Cambridge University Press.

Marshall, H. H., Carter, A. J., Rowcliffe, J. M., \& Cowlishaw, G. (2012). Linking social foraging behaviour with individual time budgets and emergent group-level phenomena. Animal Behaviour, 84, 1295-1305.

Mount, L.E. (1979). Adaptation to thermal environment. London: Arnold.

Opie, K., Atkinson, Q., Dunbar, R. \& Shultz, S: Infanticide still drives primate monogamy. Proceedings of the National Academy of Sciences, USA, 111, E1675.

Palombit, R. (1995). Inter- and intraspecific variation in the diets of sympatric siamang (Hylobates syndactylus) and lar gibbons (Hylobates lar). Folia Primatologica, 68, 321-337.

Palombit, R.A. (1997). Inter- and intraspecific variation in the diets of sympatric siamang (Hylobates syndactylus) and lar gibbons (Hylobates lar). Folia Primatologica, 68, 321-337.

Peters, R.H. (1983). Ecological implications of body size. Cambridge: Cambridge University Press.

Pollard, K. A., \& Blumstein, D. T. (2008). Time allocation and the evolution of group size. Animal Behaviour, 76, 1683-1699.

Raemaekers, J.J. (1979). Ecology of sympatric gibbons. Folia Primatologica, 31, 227245.

Reichard, U.H. (2003). Social monogamy in gibbons: the male perspective. In U.H. Reichard \& C. Boesch (Eds.), Monogamy: mating strategies and partnerships in birds, humans and other mammals, pp. 190-213. Cambridge: Cambridge 
1000

1001

1002

1003

1004

1005

1006

1007

1008

1009

1010

1011

1012

1013

1014

1015

1016

1017

1018

1019

1020

1021

1022

University Press.

Reiter, P. (2000). From Shakespeare to Defoe: malaria in England in the Little Ice Age. Emerging Infectious Diseases, 6, 1-11.

Riginos, C., 2015. Climate and the landscape of fear in an African savanna. Journal of Animal Ecology, 84, 124-133.

Rosenzweig, M.L. (1968). Net primary productivity of terrestrial communities: prediction from climatological data. American Naturalist, 102, 67-74.

Rutberg, A.T. (1983). The evolution of monogamy in primates. Journal of Theoretical Biology, 104, 93-112.

van Schaik, C.P. (1983). Why are diurnal primates living in groups? Behaviour, 87, $120-144$.

van Schaik, C.P. \& Dunbar, R.I.M. (1990). The evolution of monogamy in largebodied primates: a new hypothesis and some critical tests. Behaviour, 115, 3062.

van Schaik, C.P. \& van Hooff, J. (1983). On the ultimate causes of primate social systems. Behaviour, 85, 91-117.

van Soest, P.J. (1982). Nutritional ecology of the ruminant. Ithaca, NY: Cornell University Press.

Seyfarth, R.M. \& Cheney, D.L. (1984). Grooming, alliances and reciprocal altruism in vervet monkeys. Nature, 308, 541.

Shultz, S., Noe, R., McGraw, S. \& Dunbar, R.: A community-level evaluation of the impact of prey behavioural and ecological characteristics on predator diet composition. Proc. R. Soc. Lond., 271B, 725-732. 
1023

1024

1025

1026

1027

1028

1029

1030

1031

1032

1033

1034

1035

1036

1037

1038

1039

1040

1041

1042

1043

1044

1045

1046

1047

Shultz, S. \& Finlayson, L.V. (2010). Large body and small brain and group sizes are associated with predator preferences for mammalian prey. Behavioral Ecology, 21, 1073-1079.

Shultz, S., Noe, R., McGraw, S. \& Dunbar, R.I.M. (2004). A community-level evaluation of the impact of prey behavioural and ecological characteristics on predator diet composition. Proceedings of the Royal Society, London, 271B, 725732.

Snaith, T.V. \& Chapman, C.A. (2007). Primate group size and interpreting socioecological models: do folivores really play by different rules?. Evolutionary Anthropology, 16, 94-106.

Srikosamatara, S. (1984). Ecology of pileated gibbons in southeast Thailand. In Preuschoft, H.H., Chivers, D.J., Brockelman, W.Y. \& Creel, N. (Eds.), The lesser apes, pp. 242-257. Edinburgh: Edinburgh University Press.

Storm, P. \& de Vos, J. (2006). Rediscovery of the Late Pleistocene Punung hominin sites and the discovery of a new site Gunung Dawung in East Java. Palaeobiodiversity and Palaeoenvironments, 86, 271-281.

Sutcliffe, A.J., Dunbar, R.I.M., Binder, J. \& Arrow, H. (2012). Relationships and the social brain: integrating psychological and evolutionary perspectives. British Journal of Psychology, 103, 149-168.

Tolon, V., Dray, S., Loison, A., Zeileis, A., Fischer, C. \& Baubet, E. (2009). Responding to spatial and temporal variations in predation risk: space use of a game species in a changing landscape of fear. Canadian Journal of Zoology, 87, 1129-1137.

Turvey, S.T., Crees, J.J. \& Di Fonzo, M.M.I. (2015). Historical data as a baseline for conservation: reconstructing long-term faunal extinction dynamics in Late 
1048

1049

1050

1051

1052

1053

1054

1055

1056

1057

1058

1059

1060

1061

1062

Imperial-modern China. Proceedings of the Royal Society, London, B 20151299.

Willems, E.P. \& Hill, R.A. (2009). A critical assessment of two species distribution models: a case study of the vervet monkey (Cercopithecus aethiops). Journal of Biogeography, 36, 2300-2312.

Williamson, D.K. \& Dunbar, R.I.M. (1998). Energetics, time budgets and group size. In Lee, P.C. (Ed.), Comparative primate Ssocioecology, pp. 320-338. Cambridge: Cambridge University Press.

Wittenberger, J.F. \& Tilson, R.L. (1980). The evolution of monogamy: hypotheses and evidence. Annual Review of Ecology and Systematics, 11, 197-232.

Wrangham, R.W., Gittleman, J.L. \& Chapman, C.A. (1993). Constraints on group size in primates and carnivores: population density and day-range as assays of exploitation competition. Behavioral Ecology and Sociobiology, 32, 199209. 


\section{Legends to Figures}

1065

1066

1067

1068

1069

1070

1071

1072

1073

1074

1075

1076

1077

1078

1079

1080

1081

1082

1083

1084

1085

1086

1087

1088

Fig. 1. Flow chart for the gibbon time budget model, summarising the causal relationships between climatic and behavioural variables based on the equations given in Table 1. Solid lines: positive effects; dashed lines: negative effects.

Fig. 2. Time spent moving plotted against mean population group size. Dashed line is least squares regression line. Filled symbols: gibbons; unfilled symbols: siamang. Source: online Dataset S1.

Fig. 3. (a) Maximum ecologically tolerable group size predicted by the time budget model, plotted against observed mean group size for different gibbon (filled symbols) and siamang (unfilled symbols) populations. (b) Predicted maximum group size allowing for a $15 \%$ increase in the length of the active day. The solid line demarcates the minimum group size for demographic viability ( 2 adults plus 0.96 immatures: see text for details); dashed line in (a) is the line of equilibrium $($ Nmax $=$ observed mean $)$.

Fig. 4. Maximum group size predicted by the time budget model for different combinations of (a) latitude and altitude and (b) annual rainfall and mean temperature.

Fig. 5. Mean ( $\pm 95 \% \mathrm{CI})$ maximum group size (Nmax) predicted by the time budget model for habitats within different geographic regions. Filled circles: regions 
1089 where gibbons currently live; unfilled circles: regions where gibbons do not 1090 currently live; grey circle: gibbons historically present before 1800 AD. Dashed 1091 line: minimum group size for demographic viability (2.96 individuals: see text). 1092 Present: 18 sites within the current biogeographic distribution of gibbons within 1093 Indo-China, Sumatra and Borneo. W Java: 3 sites in west Java where gibbons 1094 occur; E Java: 8 sites in Java east of the Dieng Mountains where gibbons do not 1095

Fig. 6. Mean ( $\pm 95 \% \mathrm{CI})$ (a) feeding time, (b) moving time and (c) enforced rest time predicted by the time budget model for the regional sites shown in Fig. 5. Moving time does not include an adjustment for group size. Regions and symbols as for Fig. 5.

Fig. 7. (a) Mean $( \pm 95 \% \mathrm{CI})$ ratio of observed to predicted time spent feeding and resting for populations for which predicted $N \max <5$ (unfilled symbols) or Nmax $>5$ (filled symbols). Predicted rest time is enforced rest time. (b) Difference in 
1114

1115

rest time (observed minus predicted by model) for individual hylobatid populations plotted against difference in group size (observed minus Nmax). Source: Dataset S1.

Fig. 8. Mean observed group size for individual populations plotted against absolute latitude for the population. The best fit equation (dashed line) is Group size $=$ $3.71-0.014 *$ Lat $+0.012 *$ Lat $^{2}-0.0004 *$ Lat $^{3}\left(r^{2}=0.159, F_{3,50}=3.15, p=0.033\right)$. Source: Dataset S1. 
Table 1. Regression equations for the hylobatid model.

\begin{tabular}{|c|c|c|c|c|c|}
\hline Variable & Equation & $\mathrm{r}^{2}$ & $\mathrm{~F}$ & df & $\mathrm{p}$ \\
\hline (1) Feed time (\%) & $41.634-0.003 * \mathrm{RAIN}-0.009 * \mathrm{ALT}+0.363 * \mathrm{LAT}_{\mathrm{abs}} \Omega$ & 0.501 & 5.03 & 3,15 & 0.013 \\
\hline (2) Moving time $(\%)$ & $17.316+0.462 * \mathrm{LAT}_{\mathrm{abs}}$ & 0.166 & 3.59 & 1,18 & 0.074 \\
\hline (2a) Moving time (\%) & $5.297+0.290 * \mathrm{LAT}_{\mathrm{abs}}+3.080 * \mathrm{~N}$ & 0.220 & 1.98 & 2,14 & 0.175 \\
\hline (3) Rest $_{\mathrm{ENF}}$ time $(\%)^{\top}$ & $-23.24+1.33 * \mathrm{TEMP}+0.259 * \mathrm{LEAF}+6.12 * \mathrm{~T}_{\mathrm{moSD}}$ & \multicolumn{4}{|c|}{ from Korstjens et al. (2010) } \\
\hline (4) Social $(\%) \dagger$ & $2.968+0.109 \mathrm{~N}$ & 0.440 & 29.90 & 1,38 & $<0.00$ \\
\hline (5) Time budget & \multicolumn{5}{|l|}{$100=\mathrm{FEED}+\mathrm{MOVE}+\mathrm{REST}_{\mathrm{ENF}}+\mathrm{SING}+\mathrm{SOCIAL}$} \\
\hline$(5 \mathrm{a})$ & \multicolumn{5}{|c|}{$100=\mathrm{FEED}+(5.297+0.290 * \mathrm{LATabs}+3.080 * \mathrm{~N})+\left(\mathrm{REST}_{\mathrm{ENF}}+\mathrm{REST}_{\mathrm{FREE}}\right)+\mathrm{SING}+(2.968+0.109 * \mathrm{~N})$} \\
\hline (5b) $\mathrm{Nmax}^{\S}$ & \multicolumn{5}{|c|}{$=\left(\left(100-\right.\right.$ FEED $-(5.297+0.290 *$ LATabs $)-$ REST $\left.\left.-4.96^{\ddagger}\right)+2.968\right) /(0.109+3.080)$} \\
\hline
\end{tabular}

\section{$\Omega$ Absolute latitude}

T Rest time consists of two components: enforced rest (REST $\mathrm{ENF}_{\mathrm{f}}$, imposed on the animal by climatic conditions and its dietary strategy) and free rest $\left(\mathrm{REST}_{\mathrm{FREE}}\right)$ that represents uncommitted time that can be allocated to any other activity when required (see Korstjens et al. 2010).

$\dagger$ Recalculated from Lehmann et al (2007a)

$\S$ Maximum ecologically tolerable group size (the maximum group size that will allow the time budget to be balanced)

$\$ 4.96=$ average percentage of day devoted to singing by gibbons 
Table 2. Supplementary equations

\begin{tabular}{|c|c|c|c|c|c|}
\hline Variable & Equation & $\mathrm{r}^{2}$ & $\mathrm{~F}$ & $\mathrm{df}$ & $\mathrm{p}$ \\
\hline \multirow[t]{2}{*}{$\operatorname{TmoSD} * *$} & $10.440+0.093 * \mathrm{LAT}_{\mathrm{Abs}}-0.001 * \mathrm{ALT}-0.821 * \mathrm{TEMP}$ & & & & \\
\hline & $+0.588 * \mathrm{TEMP}_{\min }$ & 0.597 & 17.75 & 4,48 & $<0.0001$ \\
\hline Mean temperature $\left({ }^{\circ} \mathrm{C}\right)$ & $27.651-0.003 * \mathrm{ALT}-0.158 * \mathrm{LAT}_{\mathrm{Abs}}$ & 0.672 & 60.33 & 2,59 & 0.0001 \\
\hline Altitude (m) & $4145.354-147.236 *$ TEMP $+0.023 *$ RAIN & 0.575 & 37.14 & 2,55 & $<0.0001$ \\
\hline $\operatorname{Temp}_{\mathrm{var}} \dagger$ & 10.196 & & & & \\
\hline Absolute Latitude & $48.732-0.004 *$ RAIN $-1.142 *$ TEMP & 0.580 & 35.23 & 2,51 & $<0.0001$ \\
\hline Rain & $3279.523-53.609 * \mathrm{LAT}_{\mathrm{Abs}}+0.025 * \mathrm{ALT}$ & 0.286 & 10.60 & 2,52 & $<0.0001$ \\
\hline $\mathrm{Temp}_{\min }\left({ }^{\circ} \mathrm{C}\right)$ & $-5.776+1.033 * \mathrm{TEMP}$ & 0.922 & 623.63 & 1,53 & $<0.0001$ \\
\hline \multirow[t]{2}{*}{ Territory size (ha) } & $2498.88+0.077 * \mathrm{ALT}-477.830 * \mathrm{TEMP}_{\min }+401.718 * \mathrm{TEN}$ & & & & \\
\hline & $-477.03 * \mathrm{TEMP}_{\mathrm{var}}-32.260 *$ TEMPmoSD $-0.032 * \mathrm{RAIN}$ & 0.894 & 19.60 & 6,14 & $<0.0001$ \\
\hline \multirow[t]{2}{*}{ Leaf in $\operatorname{diet}(\%)$} & $99.430-1.000 * \mathrm{LAT}_{\mathrm{abs}}+0.009 * \mathrm{ALT}+7.012 * \mathrm{TEMP}_{\mathrm{var}}+$ & & & & \\
\hline & $7.879 * \mathrm{TEMP}_{\min }-9.779 * \mathrm{TEMP}_{\max }$ & 0.611 & 5.04 & 5,16 & 0.006 \\
\hline Fruit in $\operatorname{diet}(\%)$ & $-51.27+10.65 * \mathrm{TEMP}-7.71 * \mathrm{TEMP}_{\min }$ & 0.382 & 6.19 & 2,20 & 0.008 \\
\hline Active day (hr) ${ }^{\Omega}$ & $11.273-0.001 *$ RAIN & 0.905 & 19.15 & 1,2 & 0.048 \\
\hline
\end{tabular}


** Standard deviation of monthly mean temperatures across the year

$\uparrow$ Difference between mean monthly maximum and mean monthly minimum temperature $\Omega$ Gibbons only 
Table 3. Time budget differences between siamang and gibbons

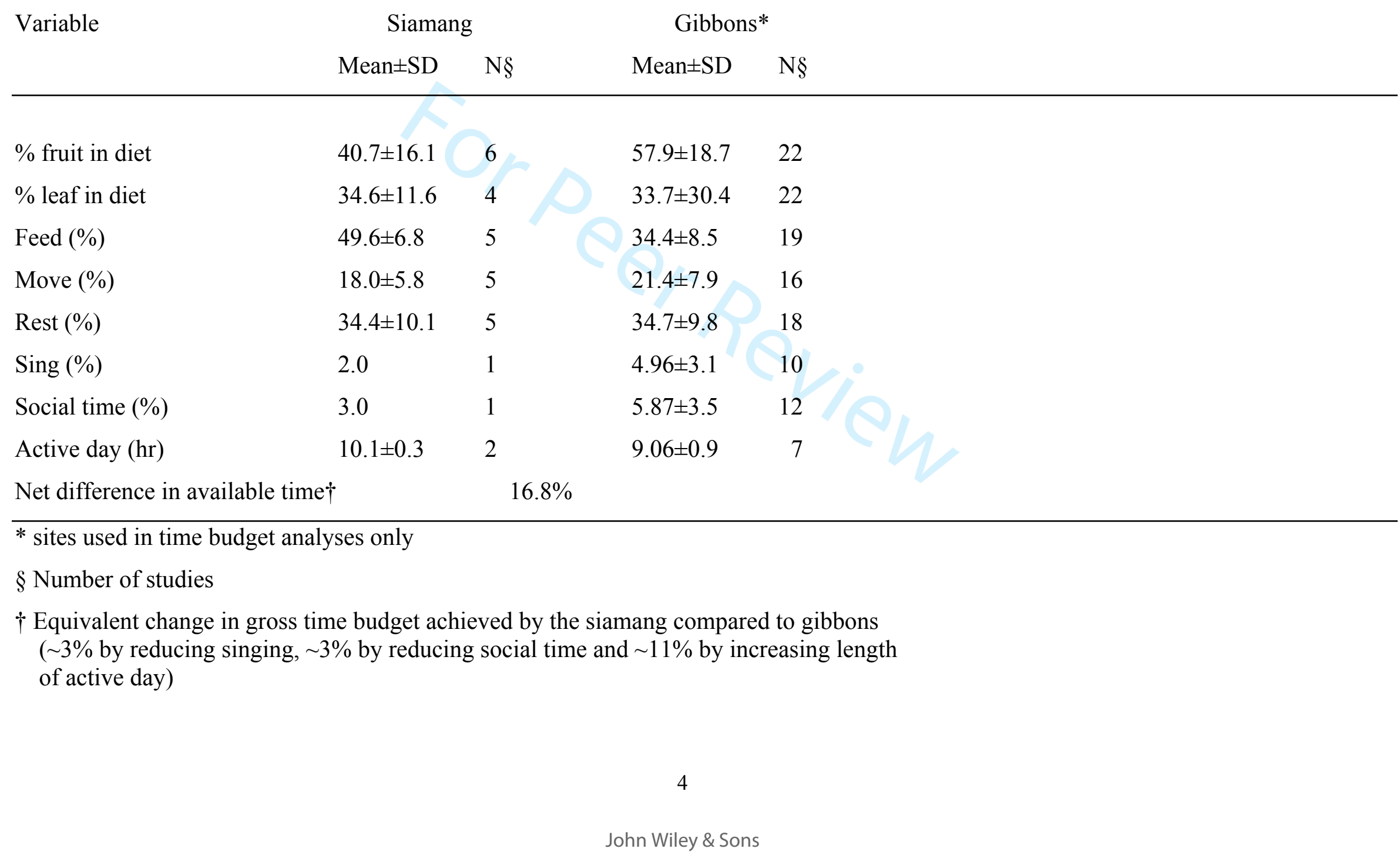


Table 4. Comparison of climatic variables between southwest China (where gibbons currently exist) and southeast China (where they were present historically, but no longer are).

\begin{tabular}{|c|c|c|c|c|c|c|c|}
\hline Provinces of China & Gibbons present & TEMP & $\mathrm{TEMP}_{\text {min }}$ & $\mathrm{TEMP}_{\max }$ & TEMP $_{\text {var }}$ & $\mathrm{TEMP}_{\mathrm{moSD}}$ & RAIN \\
\hline Southwest & current & 20.6 & 16.5 & 24.6 & 8.1 & 3.8 & 1973 \\
\hline \multirow[t]{3}{*}{ Southeast } & historical & 16.6 & 12.5 & 20.9 & 9.7 & 8.1 & 1163 \\
\hline & $\mathrm{F}_{1,15}$ & 2.50 & 1.88 & 2.61 & 0.21 & 19.97 & 9.22 \\
\hline & $\mathrm{p}$ & 0.135 & 0.191 & 0.127 & 0.657 & 0.0005 & 0.008 \\
\hline
\end{tabular}




\title{
Environment and Time as Constraints on the Biogeographical Distribution of Gibbons
}

\author{
R.I.M. Dunbar, Susan M. Cheyne, Daoying Lan, Amanda Korstjens, \\ Julia Lehmann \& G. Cowlishaw
}

Online Supplementary Material

\section{Alternative model equations}

Table S1 provides alternative multivariate equations for feeding and moving time generated by the backwards regression model. Most of the slope coefficients are similar across the alternative equations. However, note that the magnitude of the effect of group size on moving time for Equation (2c) is considerably less. Nonetheless, the values for both Equations (2a) and (2c) straddle the observed value for the chimpanzee model.

Table S2 gives the correlation values for maximum ecologically tolerable group size predicted by the original model based on Table 1 in the main text and the various alternative feeding and moving time equations given in Table S1. All alternative statistical models yield predicted maximum group sizes that correlate significantly with those predicted by the original model based on the equations of Table 1 .

Fig. S1 plots predicted maximum group size for individual study sites in the main dataset (online Dataset S1) against the equivalent value predicted by substituting the various alternative feeding and moving time equations. Alternative feeding time equations do not have a significant effect on predicted maximum group size. Note that the alternative moving time equation predicts slightly larger group sizes than those predicted by the original model of Table 1 because the effect of group size on moving time in Equation $2 \mathrm{c}$ is lower (1.72 vs 3.08), yielding slightly larger group sizes. Nonetheless, the difference in the size of the largest groups predicted is modest ( $25 \mathrm{vs}$ 15), the outcomes do not differ significantly (Table S2). Hence, using these alternative equations does not change any of the main conclusions. 
Table S1. Alternative regression equations for feeding and moving time for the hylobatid model.

\begin{tabular}{|c|c|c|c|c|c|}
\hline Variable & Equation & $\mathrm{r}^{2}$ & $\mathrm{~F}$ & df & $\mathrm{p}$ \\
\hline (1) Feed time $(\%)$ & $41.634+0.363 * \mathrm{LAT}_{\mathrm{abs}}-0.009 * \mathrm{ALT}-0.003 * \mathrm{RAIN}$ & 0.501 & 5.03 & 3,15 & 0.013 \\
\hline \multirow[t]{2}{*}{ (1a) } & \multicolumn{5}{|c|}{$53.955+0.243 * \mathrm{LAT}-0.010 * \mathrm{ALT}-0.472 * \mathrm{TEMP}+0.243 * \mathrm{TEMPVAR}-0.004 * \mathrm{RAIN}$} \\
\hline & & 0.340 & 2.86 & 5,13 & 0.059 \\
\hline \multirow[t]{2}{*}{$(1 b)$} & \multicolumn{5}{|c|}{$55.879+0.279 *$ LATtabs $-0.010 *$ ALT $-0.485 *$ TEMP $-.004 *$ RAIN } \\
\hline & & 0.520 & 3.80 & 4,14 & 0.027 \\
\hline (1c) & $33.230+0.469 *$ LATabs $-0.009 *$ ALT & 0.461 & 6.85 & 2,16 & 0.007 \\
\hline (2) Moving time (\%) & $17.316+0.462 * \mathrm{LAT}_{\mathrm{abs}}$ & 0.273 & 5.25 & 1,14 & 0.038 \\
\hline$(2 a)$ & $5.297+0.290 * \mathrm{LAT}_{\mathrm{abs}}+3.080 * \mathrm{~N}$ & 0.220 & 1.98 & 2,14 & 0.175 \\
\hline$(2 b)$ & $29.196+0.306 *$ LAT $-0.365^{*}$ TEMPmax & 0.294 & 2.71 & 2,13 & 0.104 \\
\hline$(2 c)$ & $19.409+0.303 *$ LATabs $-0.275 *$ TEMPmax $+1.718 * \mathrm{~N}$ & 0.312 & 1.81 & 3,12 & 0.199 \\
\hline
\end{tabular}


Table S2. Correlations between maximum group size predicted by the original model of Table 1 and a model using the different equations for feeding and moving time given in Table S1, for the actual hylobatid study sites (as listed in online Dataset S1). In each case, one equation is substituted, with all the remaining equations as in the original model of Table 1.

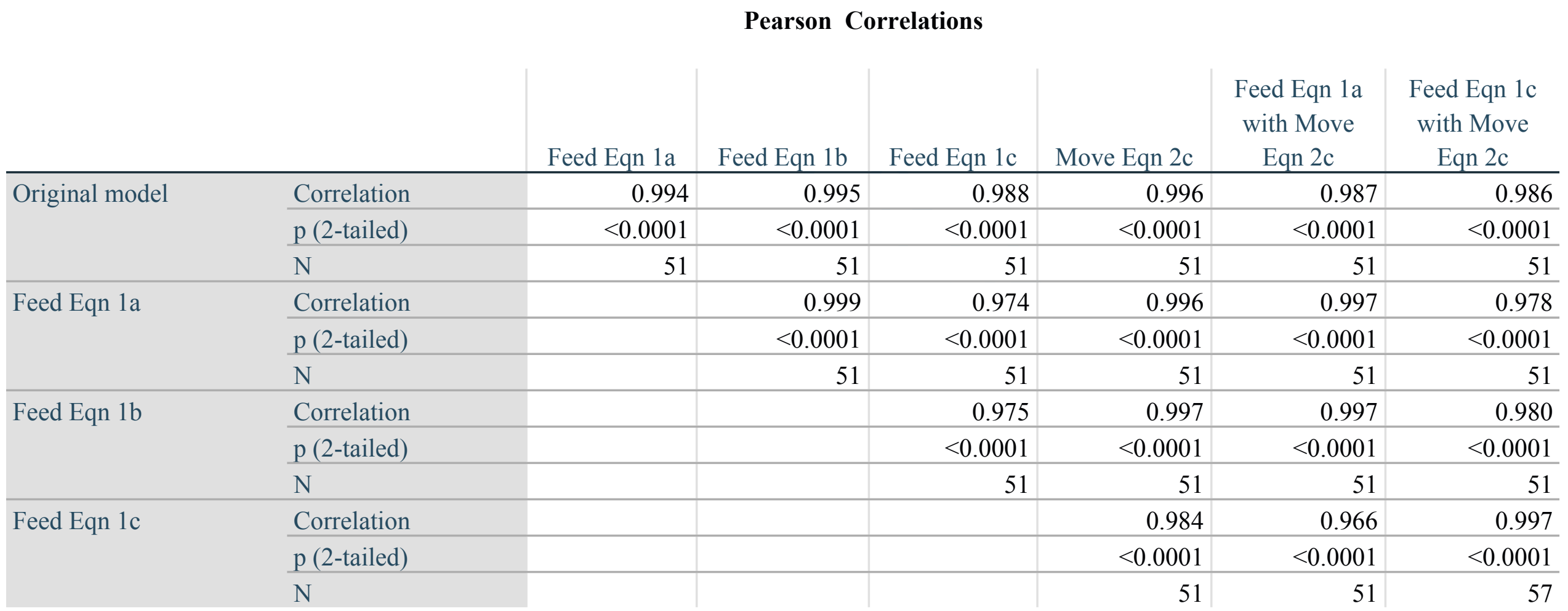




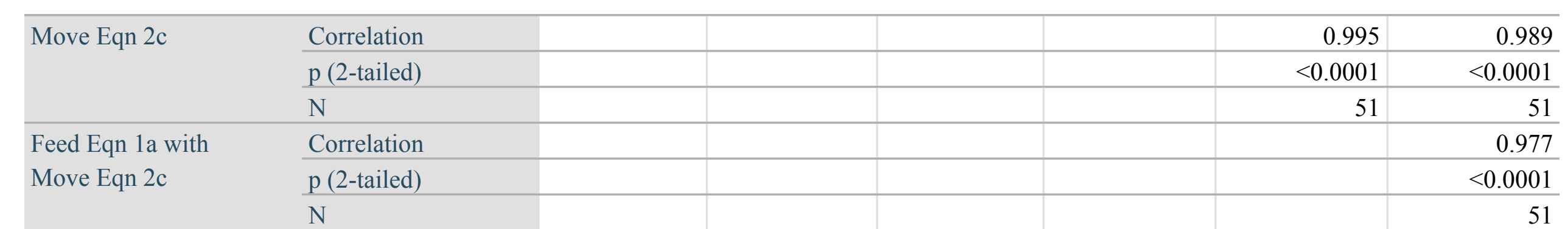




\section{Figure S1}

Maximum group size predicted by the original model using the Table 1 equations plotted against maximum group size for all populations in the sample of studies (Dataset S1), using the alternative Feed and Move equations given in Table S1. Except for the last pair of graphs, each alternative equation is substituted individually, and all other equations are held constant as in the original model of Table 1. Filled symbols: gibbon populations; unfilled symbols: siamang populations. Dashed line: line of equivalence (the predicted maximum group size is the same for both models).
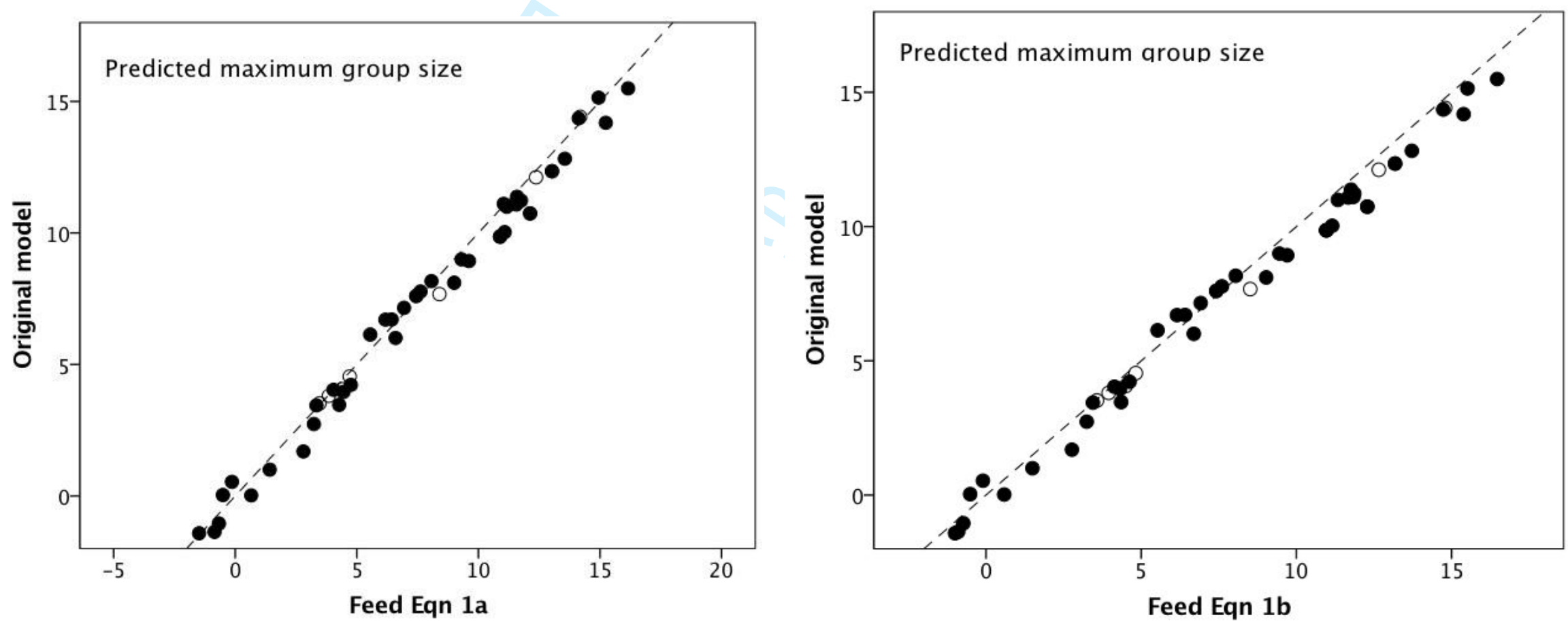
Fig. S1 (contd)
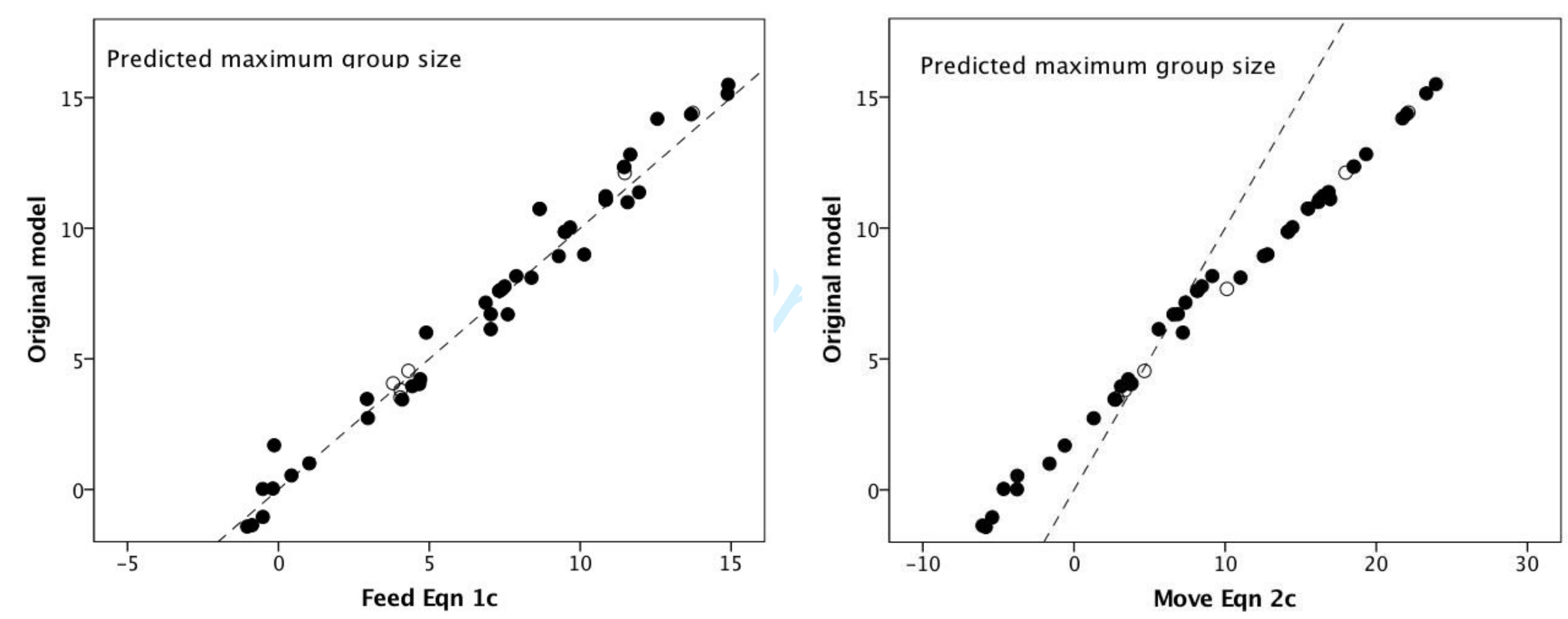
Fig. S1 (contd)
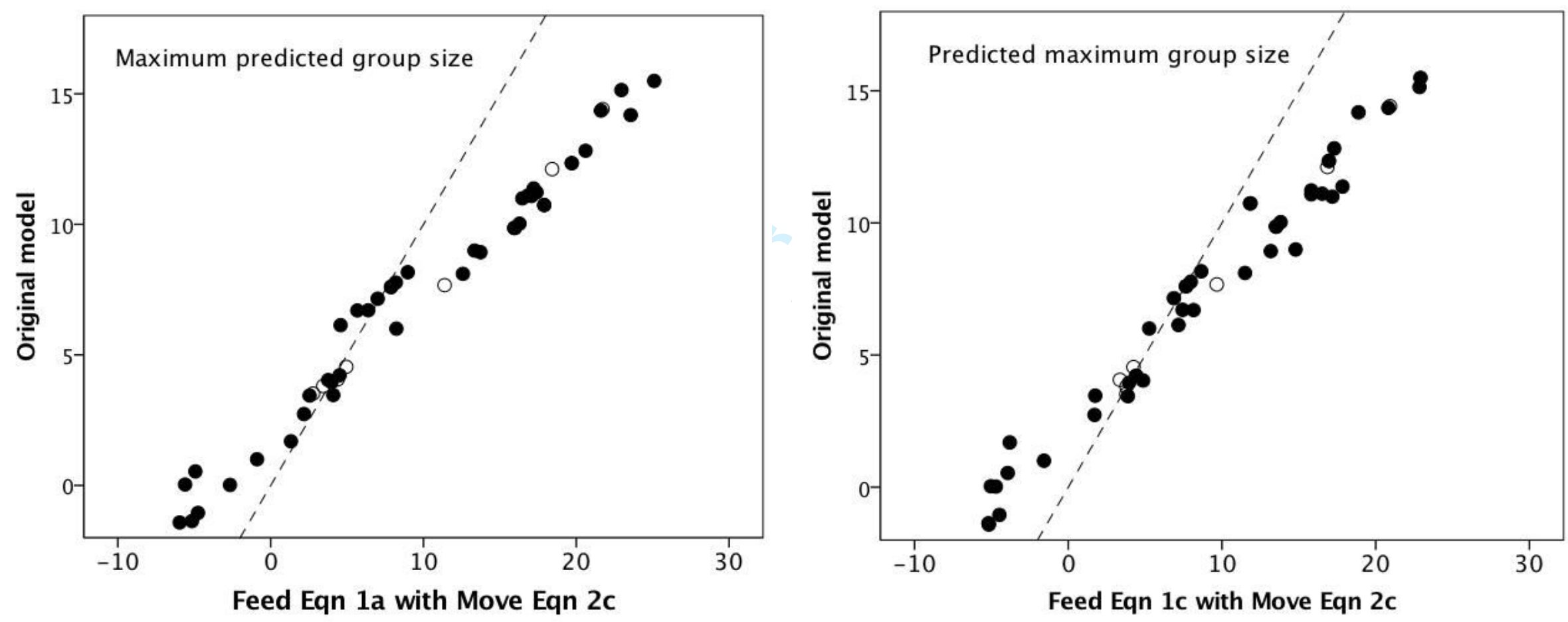


\section{Model predictions}

Fig. S2 plots the mean ( $\pm 95 \% \mathrm{CI})$ predicted maximum group size (Nmax) for sites in countries where hylobatids are known to live and those in adjacet geographical regions (which should be accessible to them) where they do not. These values are calculated from the climate data in Dataset $S 2$ for those regions listed as within their current geographic range, plus SE China (essentially the provinces where gibbons occurred prior to 1800), NE India (the area north and west of the Brahmaputra in Bangladesh and northeastern India), and central and eastern Java. Indonesia east of the Wallace Line is excluded.

The difference is highly significant (means 2.92 vs $6.8, \mathrm{~N}=31$ and 23, respectively; $\left.\mathrm{F}_{1,52}=10.71, \mathrm{p}=0.002\right)$. Note that, in areas where gibbons do not live, half the Nmax values are below the group size required for demographic viability (2.96 individuals), and most are below the observed mean size of 4.01 individuals. In contrast, all values for locations where gibbons live are above the observed mean group size.

\section{Figure S2}

Mean ( $\pm 95 \mathrm{CI})$ predicted maximum group size (Nmax) for sites in countries where hylobatids are currently found, compared to that for geographically adjacent areas where they do not now occur (see main text for details). The solid line is the calculated minimum group size for demographic viability (2.96 individuals of all ages: see main text); the dashed line is the observed mean group size across all gibbon populations. Source: Dataset $S 2$

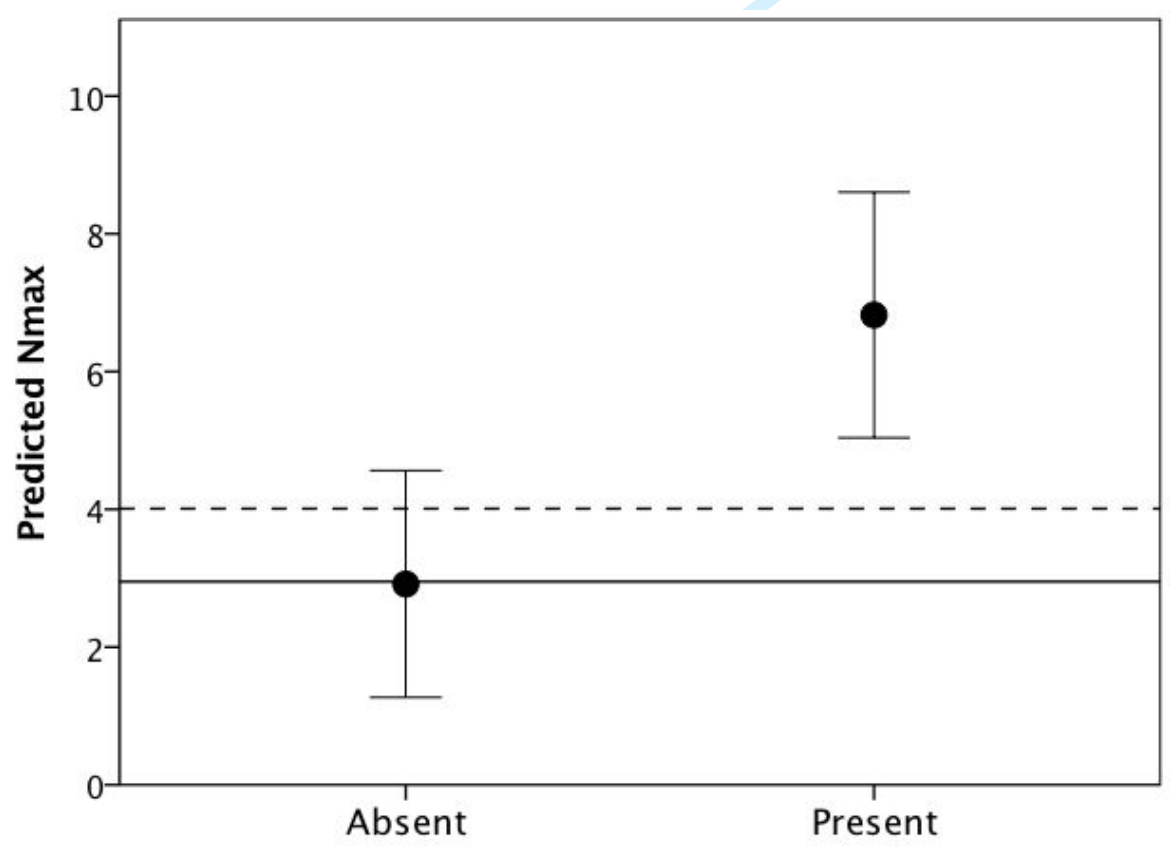




\section{Speed of travel}

We calculate average speed of travel across the day as day journey length (in metres) divided by the number of hours in the day (12) multiplied by the proportion of the day devoted to moving. Speed of travel is weakly predicted by latitude, altitude and temperature:

$$
\operatorname{SPEED}(\mathrm{m} / \mathrm{hr})=-621.2-25.7 * \mathrm{LAT}_{\mathrm{Abs}}+0.4 * \mathrm{ALT}+46.5 * \mathrm{TEMP}
$$

$\left(\mathrm{r}^{2}=0.674, \mathrm{~F}_{3,7}=1.94, \mathrm{p}=0.211\right)$.

Fig. S3(a) plots speed against absolute latitude and mean temperature. There is a very slight suggestion that the relationship might be quadratic (U-shaped) in temperature, with speed increasing when ambient temperatures are both low and high, with a minimum at temperatures around $20^{\circ} \mathrm{C}$. Alternatively, the relationship may be better described by a power curve in which speed increases dramatically above $\sim 22^{\circ} \mathrm{C}$ at latitudes $<5^{\circ}$ either side of the equator.

\section{Figure S3(a)}

Mean speed for individual gibbon (filled symbols) and siamang (unfilled symbols) plotted against mean temperature and absolute latitude of the study site, assuming a 12-hour tropical day.

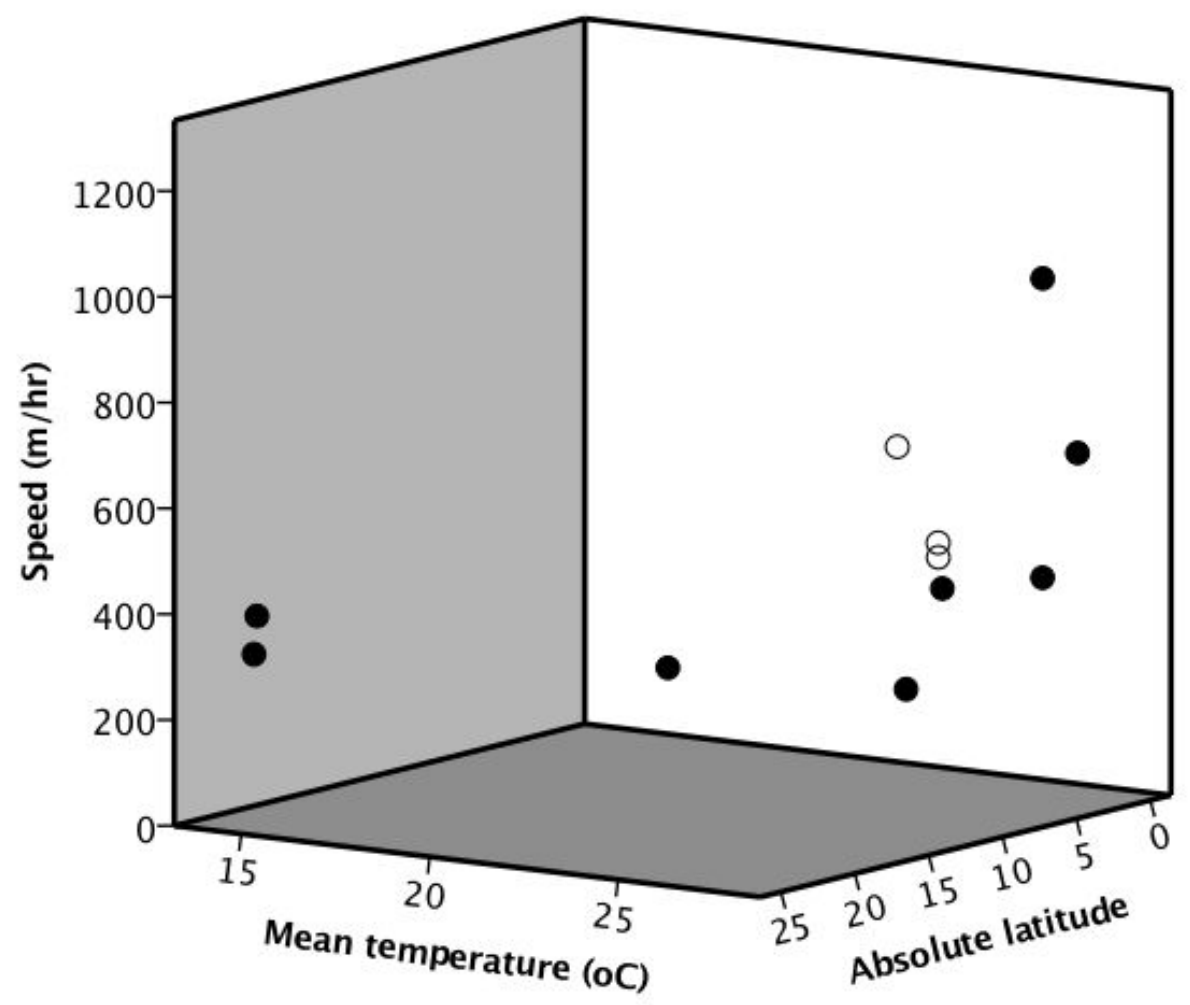


Many gibbon populations retire to nest several hours before sunset, with length of active daylength best predicted by mean rainfall (Table 2). To check whether a shorter active day makes any difference to these results, we recalculated speed as a function of actual length of active day using the equation given in Table 2 to predict length of active day from rainfall for each site. Aside from a slight uniform increase in speed, the transformation has no effect (Fig. S3b).

\section{Figure S3(b)}

Mean speed for individual gibbon (filled symbols) and siamang (unfilled symbols) plotted against mean temperature and absolute latitude of the study site, with speed calculated for active day length (estimated using the equation in rainfall from Table 2).

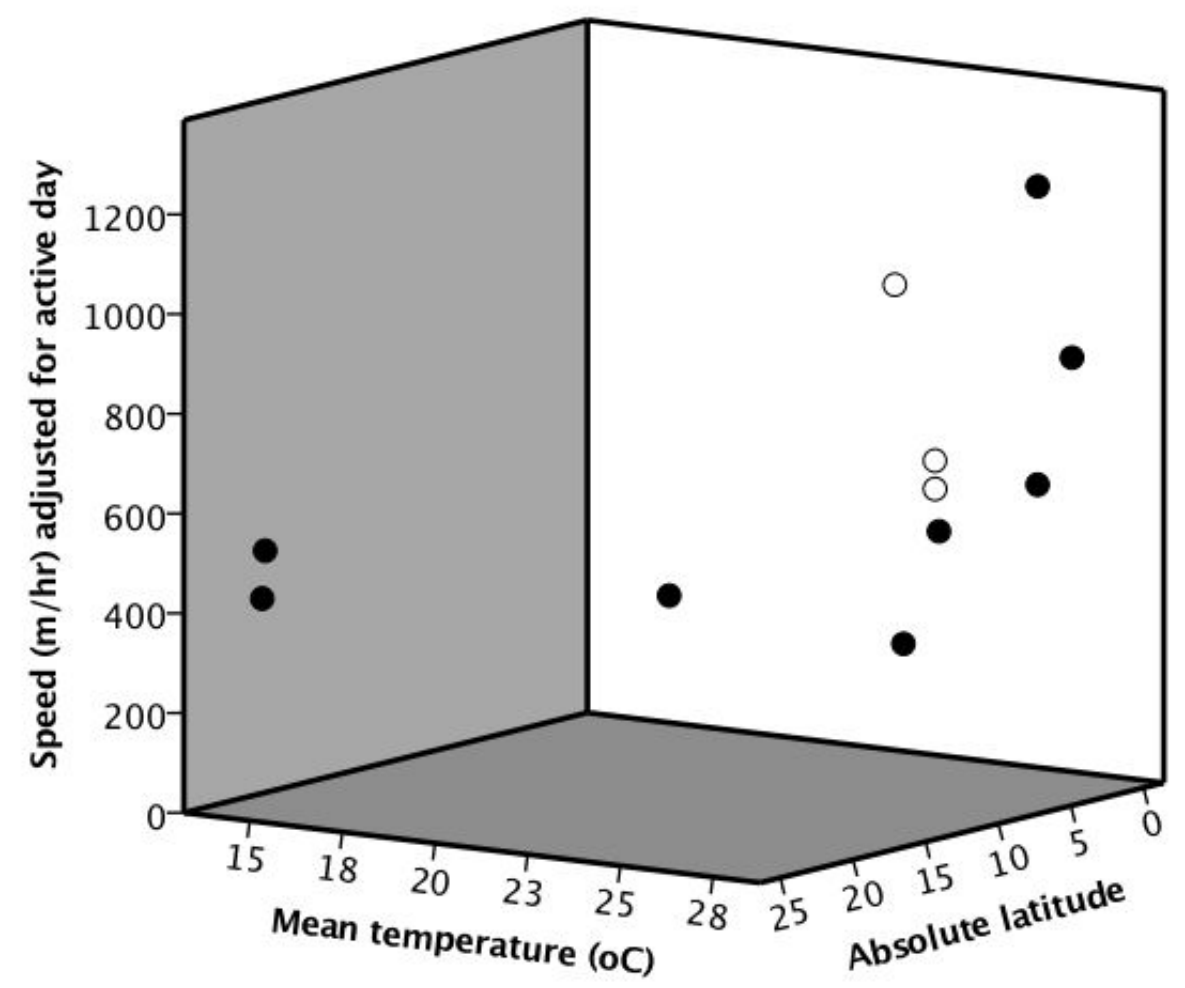




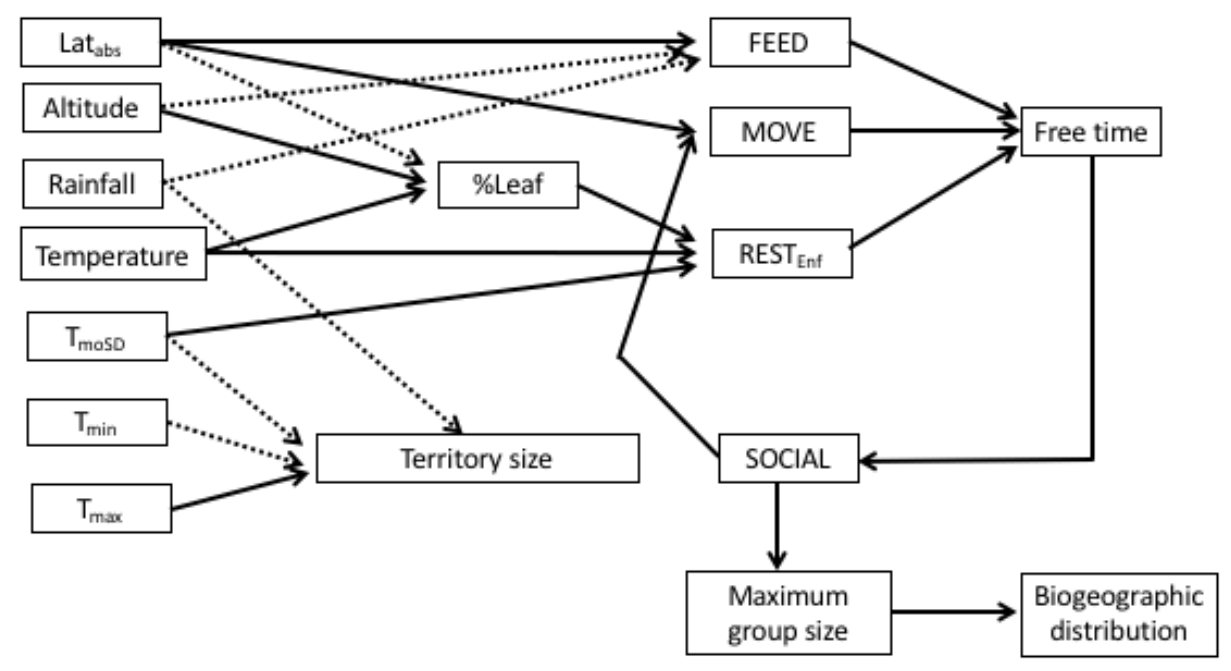




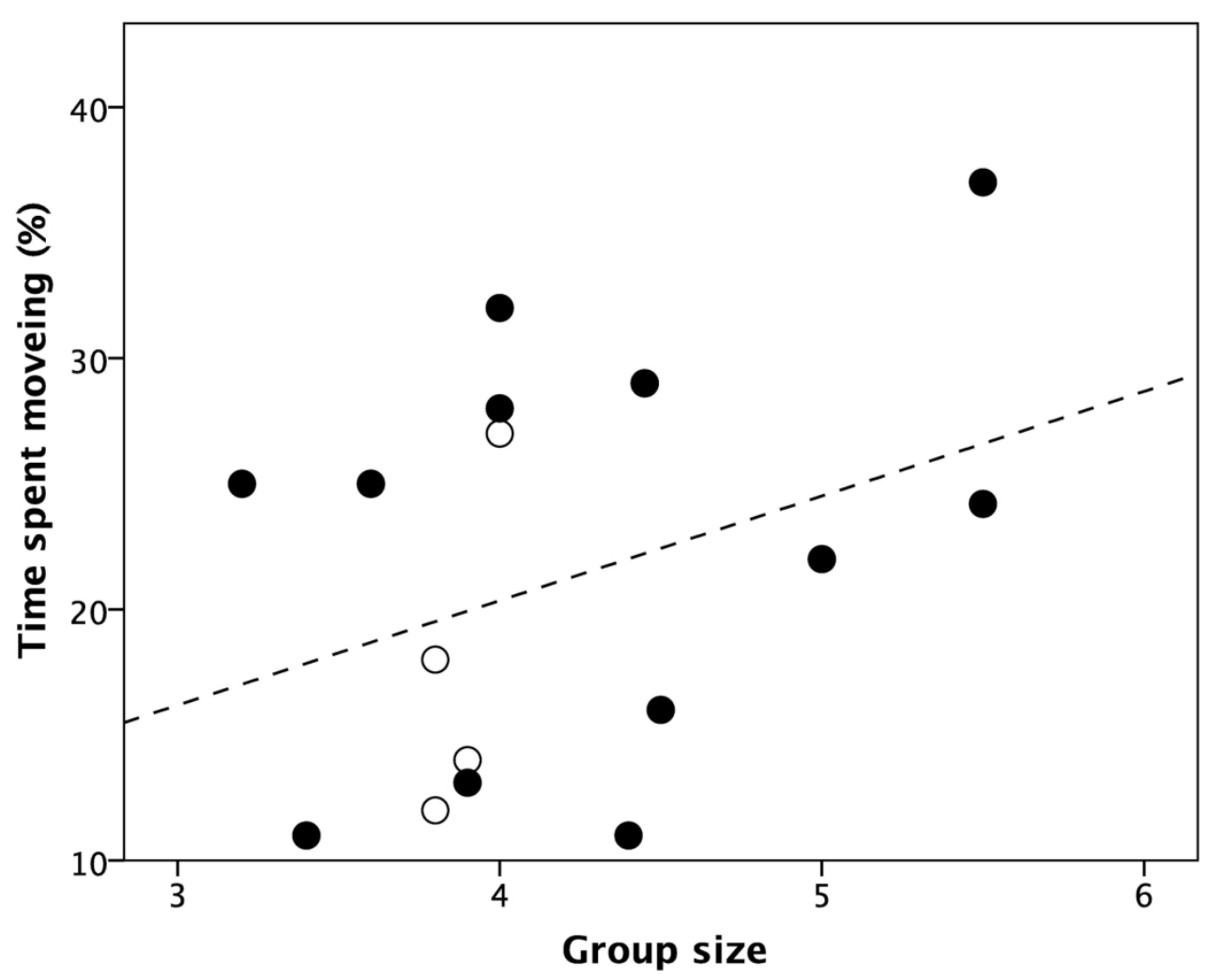

Fig. 2

$165 \times 131 \mathrm{~mm}(300 \times 300 \mathrm{DPI})$ 


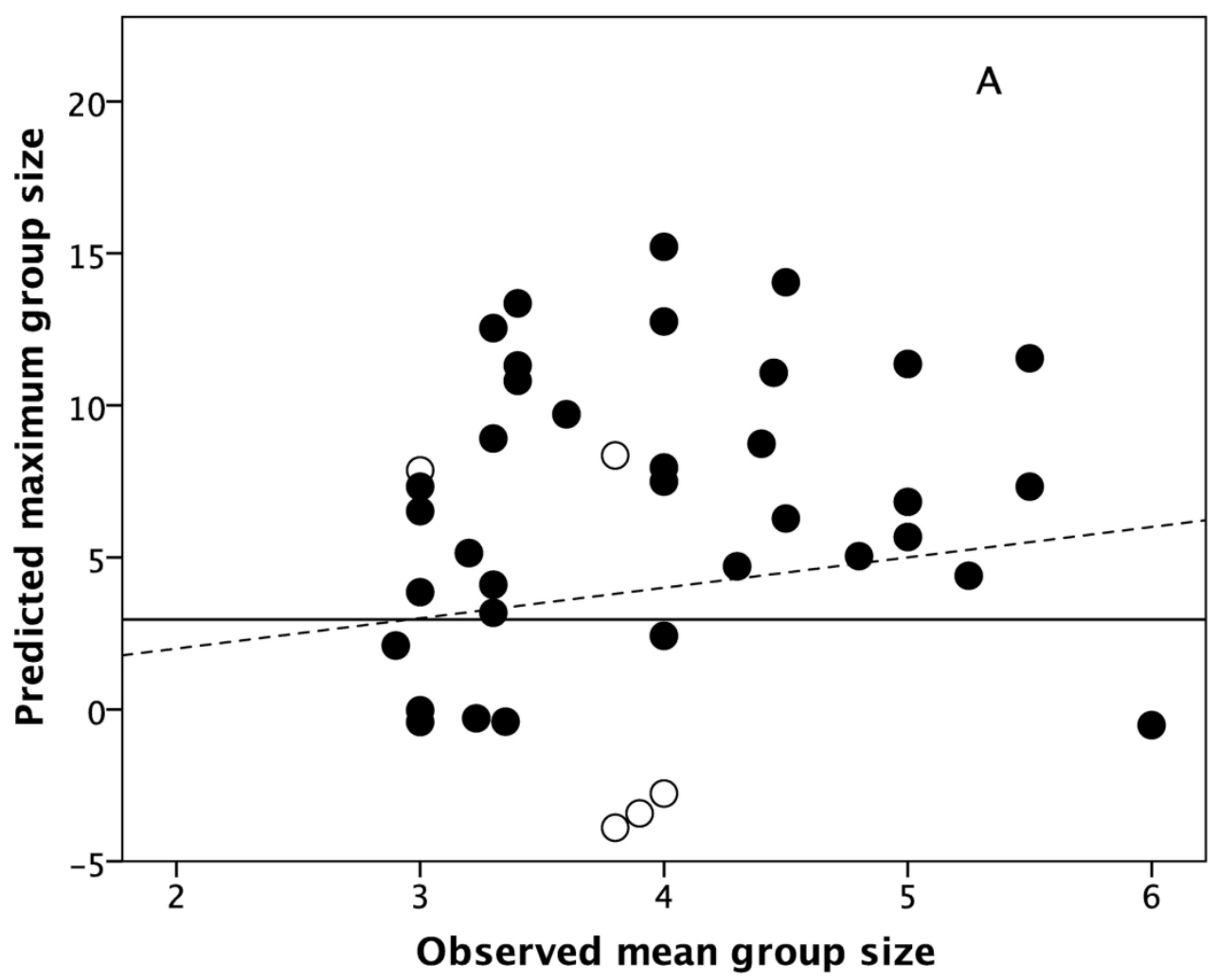

FIG. 3A

$165 \times 131 \mathrm{~mm}(300 \times 300$ DPI $)$ 


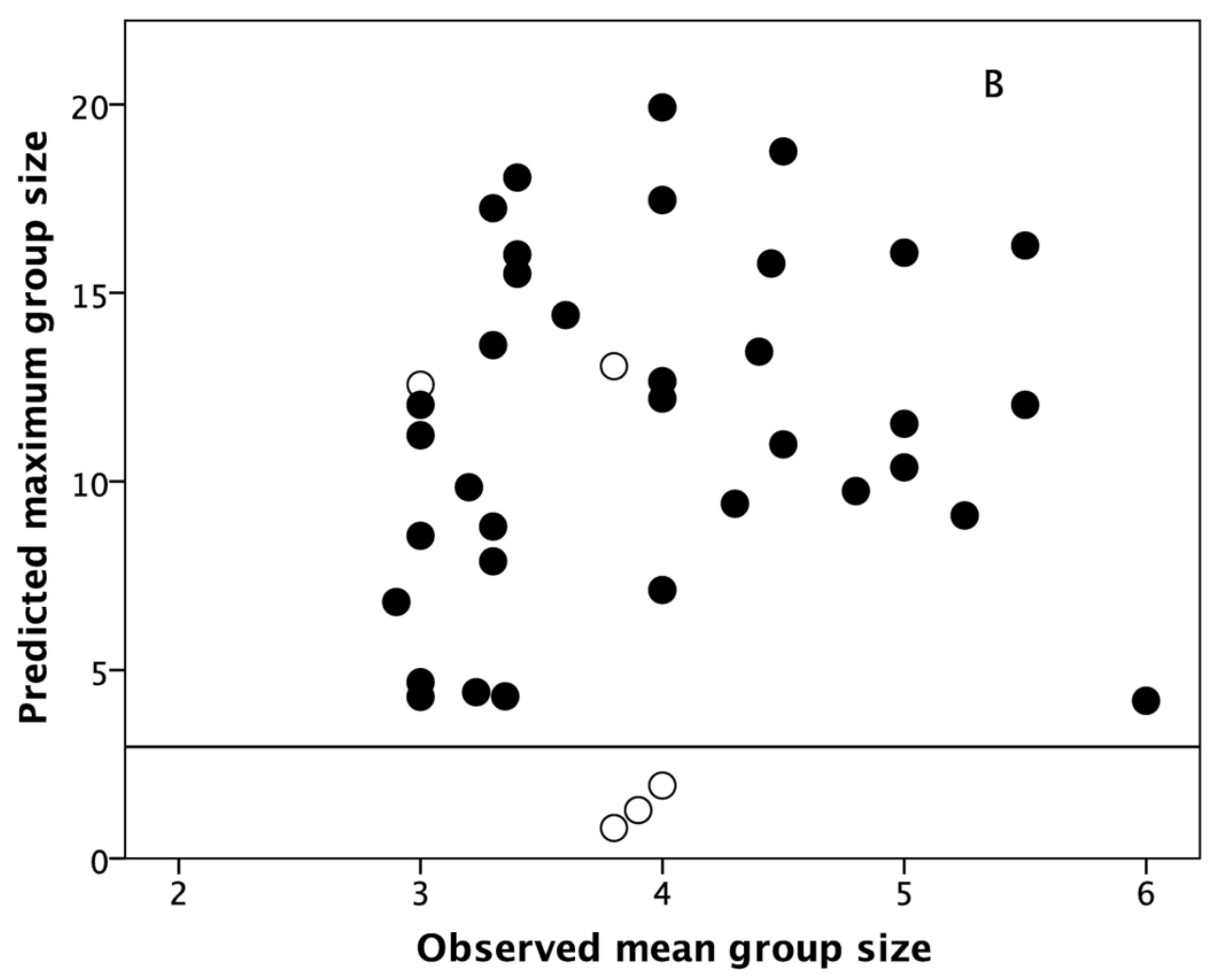

FIG. 3B

$165 \times 131 \mathrm{~mm}(300 \times 300 \mathrm{DPI})$ 


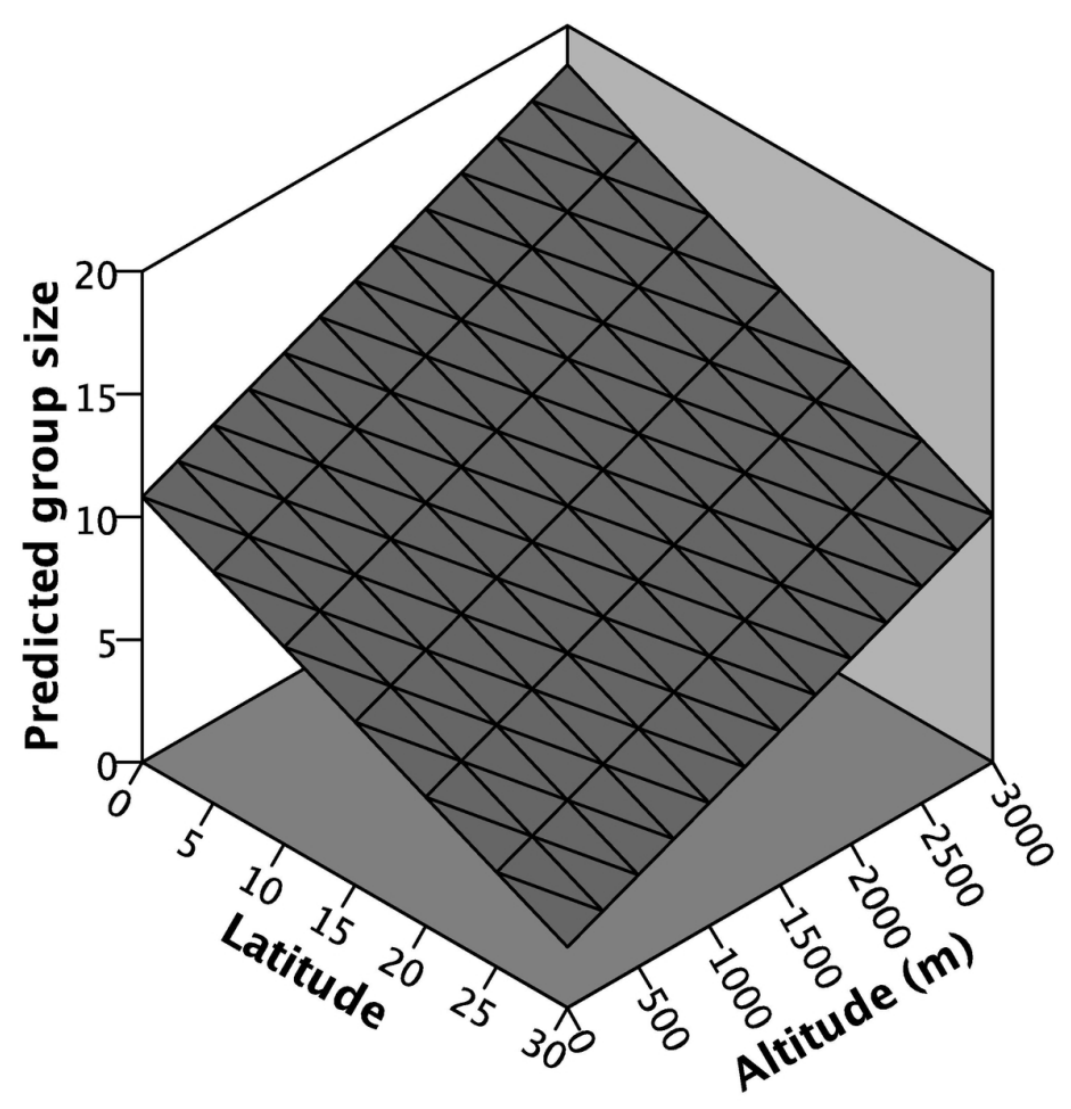

Fig. 4A

$123 \times 123 \mathrm{~mm}(300 \times 300 \mathrm{DPI})$ 


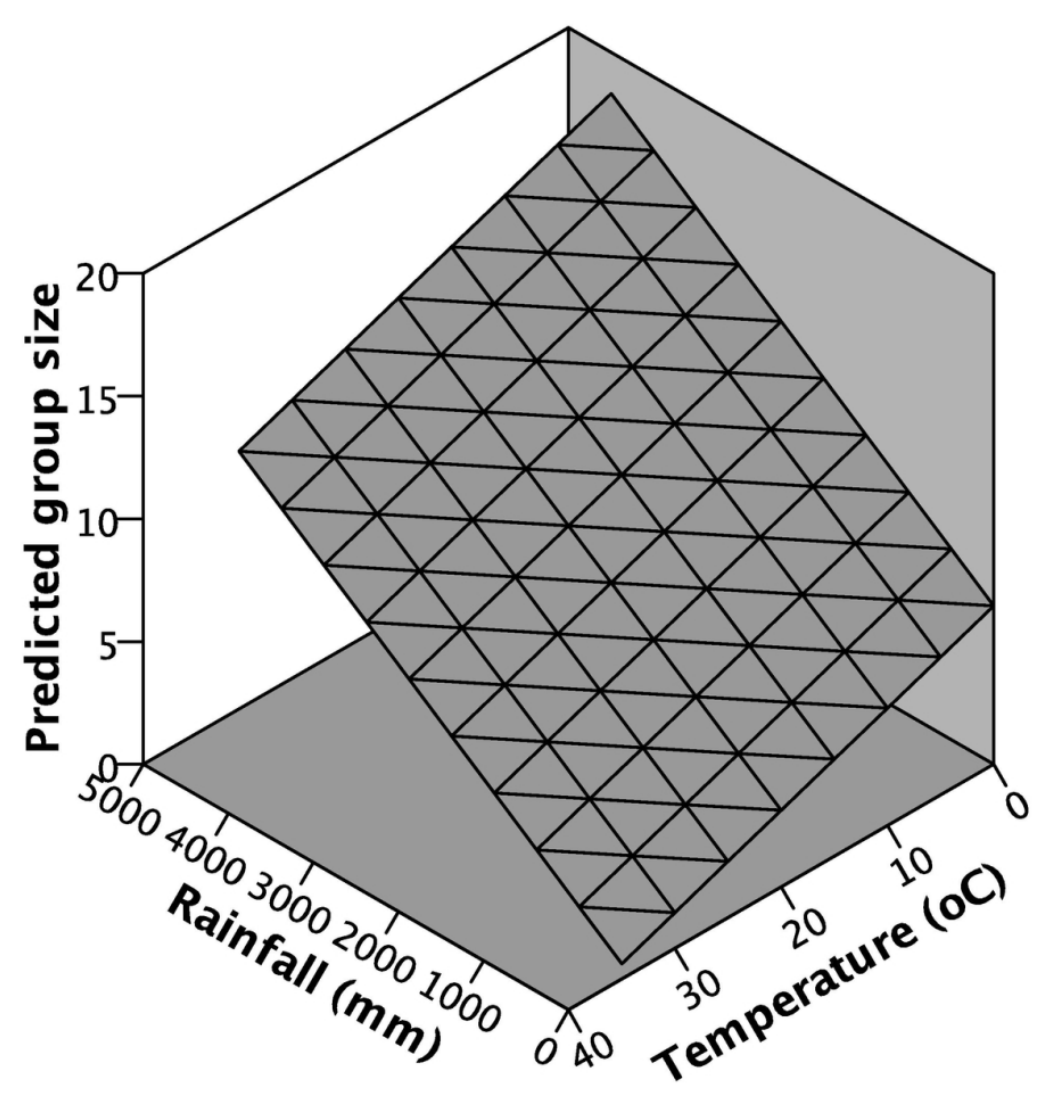

Fig. 4B

$123 \times 123 \mathrm{~mm}(300 \times 300$ DPI $)$ 


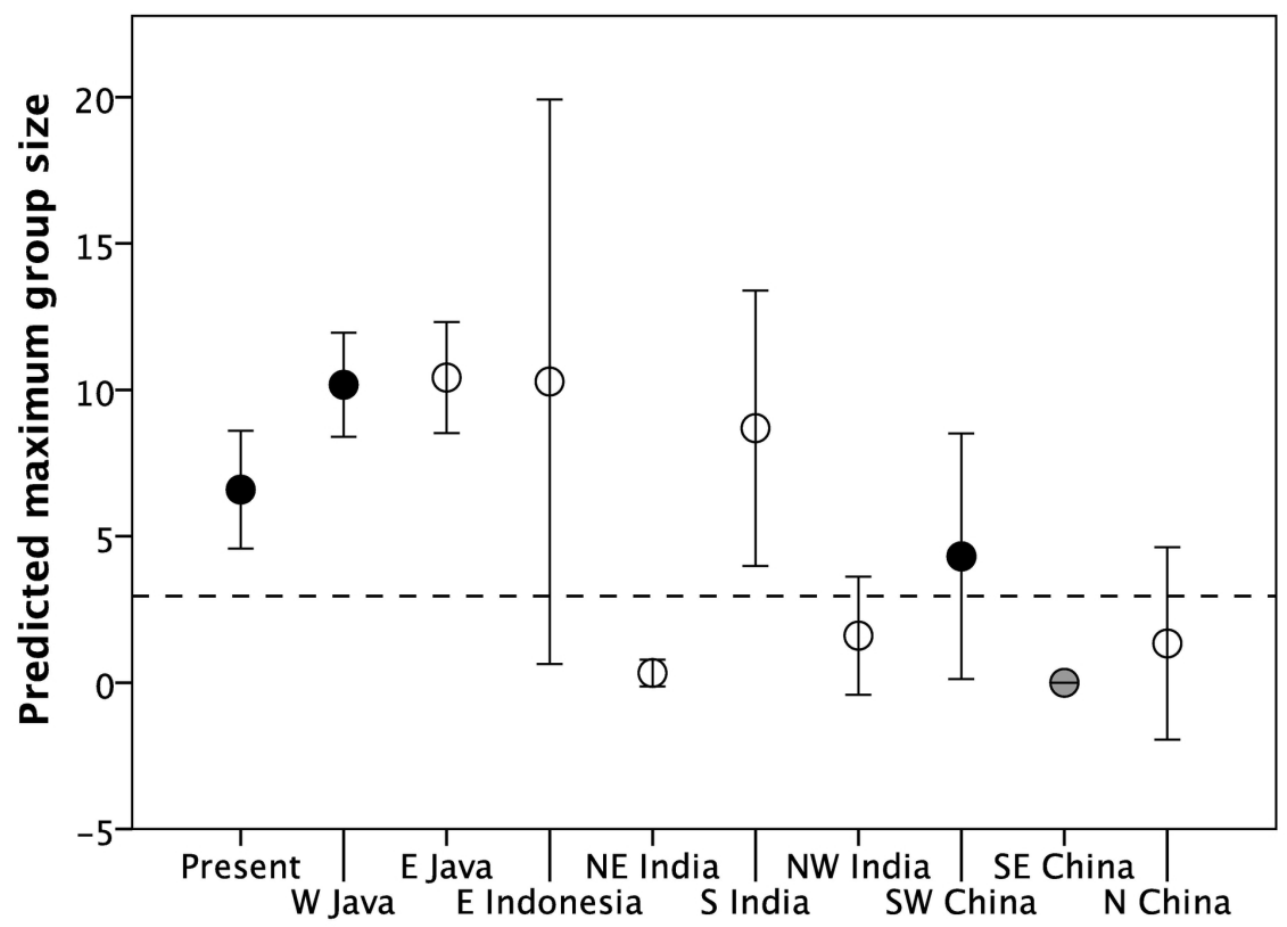

FIG. 5

$165 \times 131 \mathrm{~mm}(300 \times 300 \mathrm{DPI})$ 


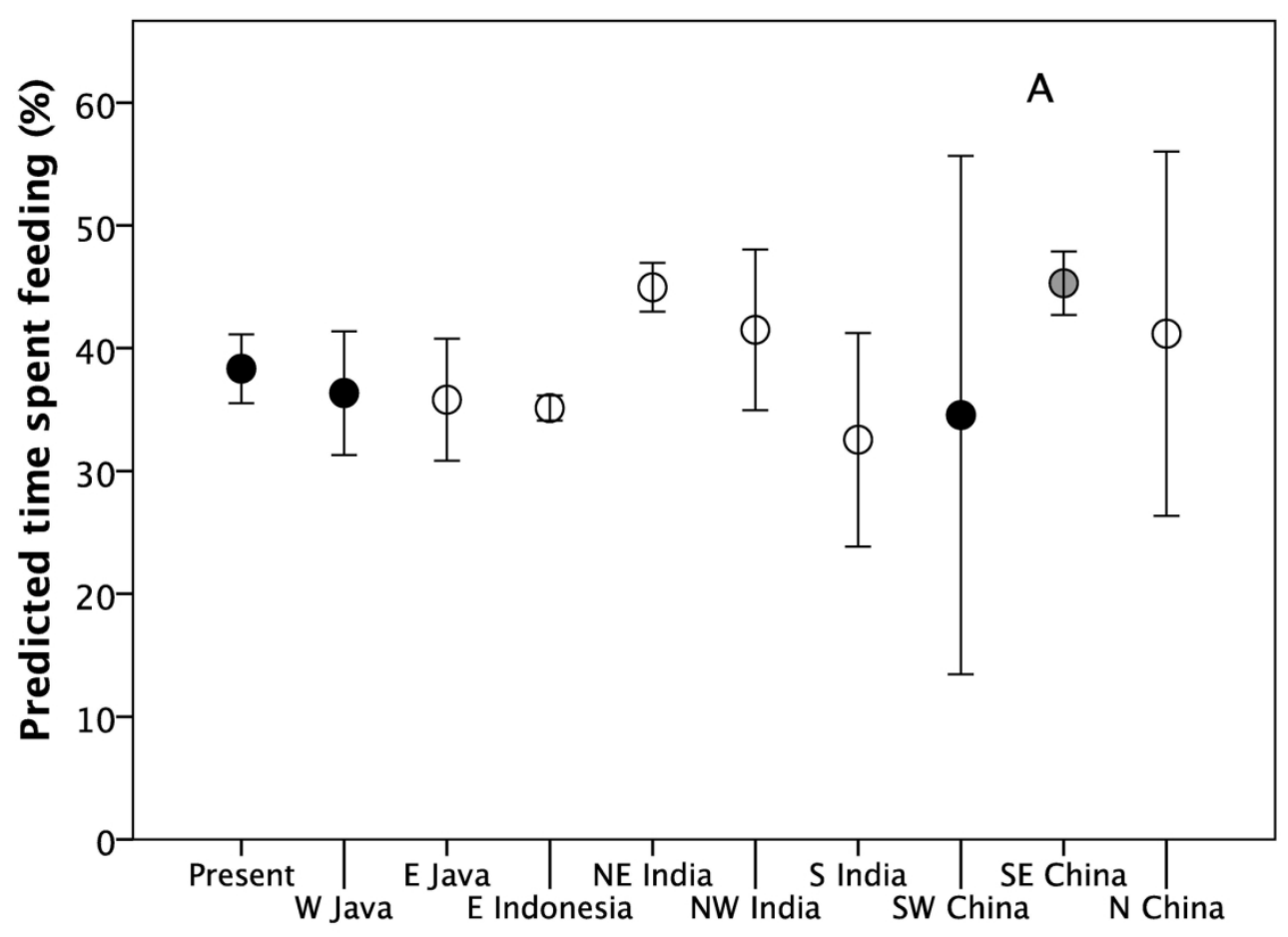

Fig. $6 \mathrm{~A}$

$165 \times 131 \mathrm{~mm}(300 \times 300 \mathrm{DPI})$

John Wiley \& Sons 


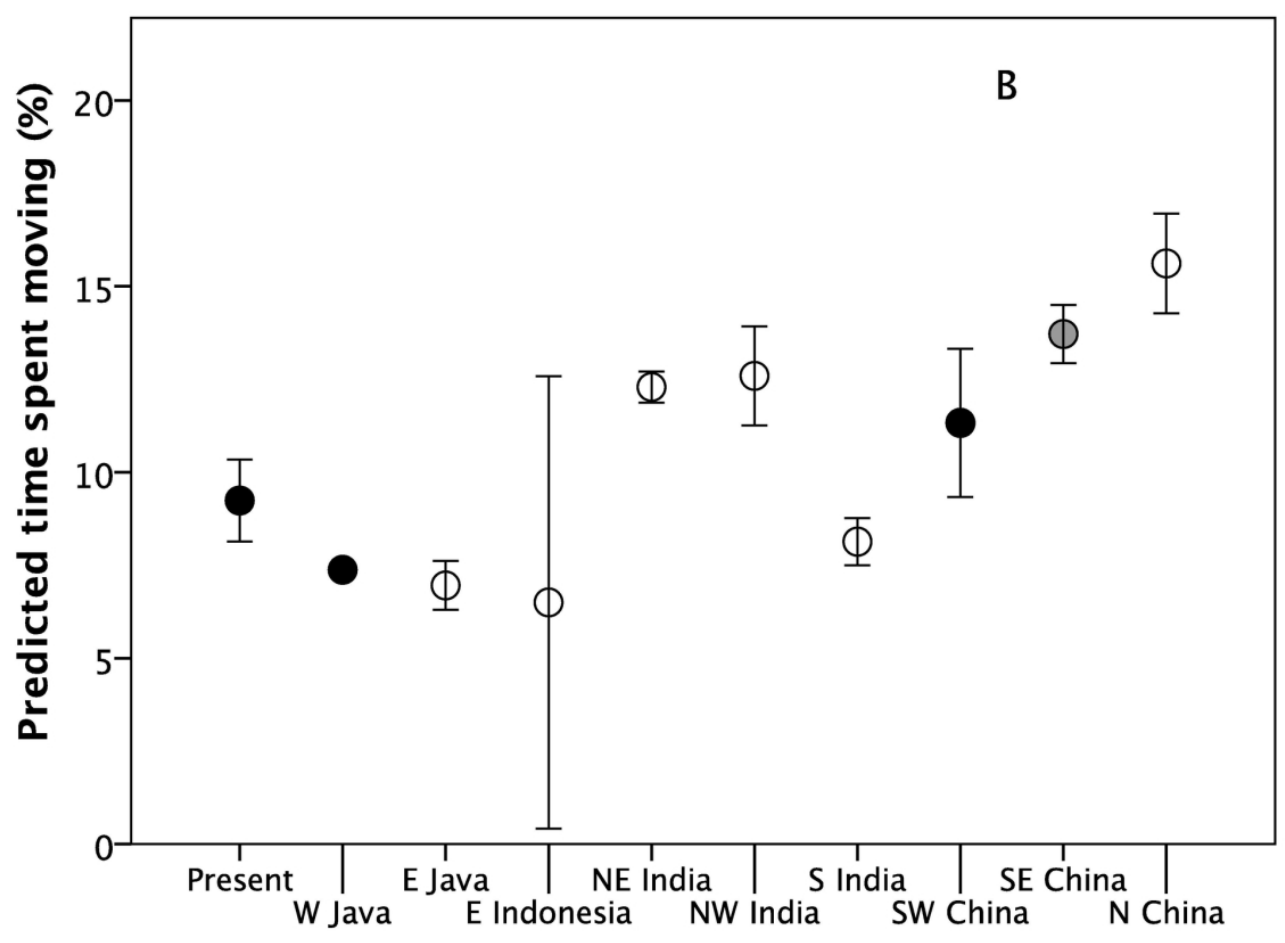

Fig. 6B

$165 \times 131 \mathrm{~mm}(300 \times 300$ DPI $)$ 


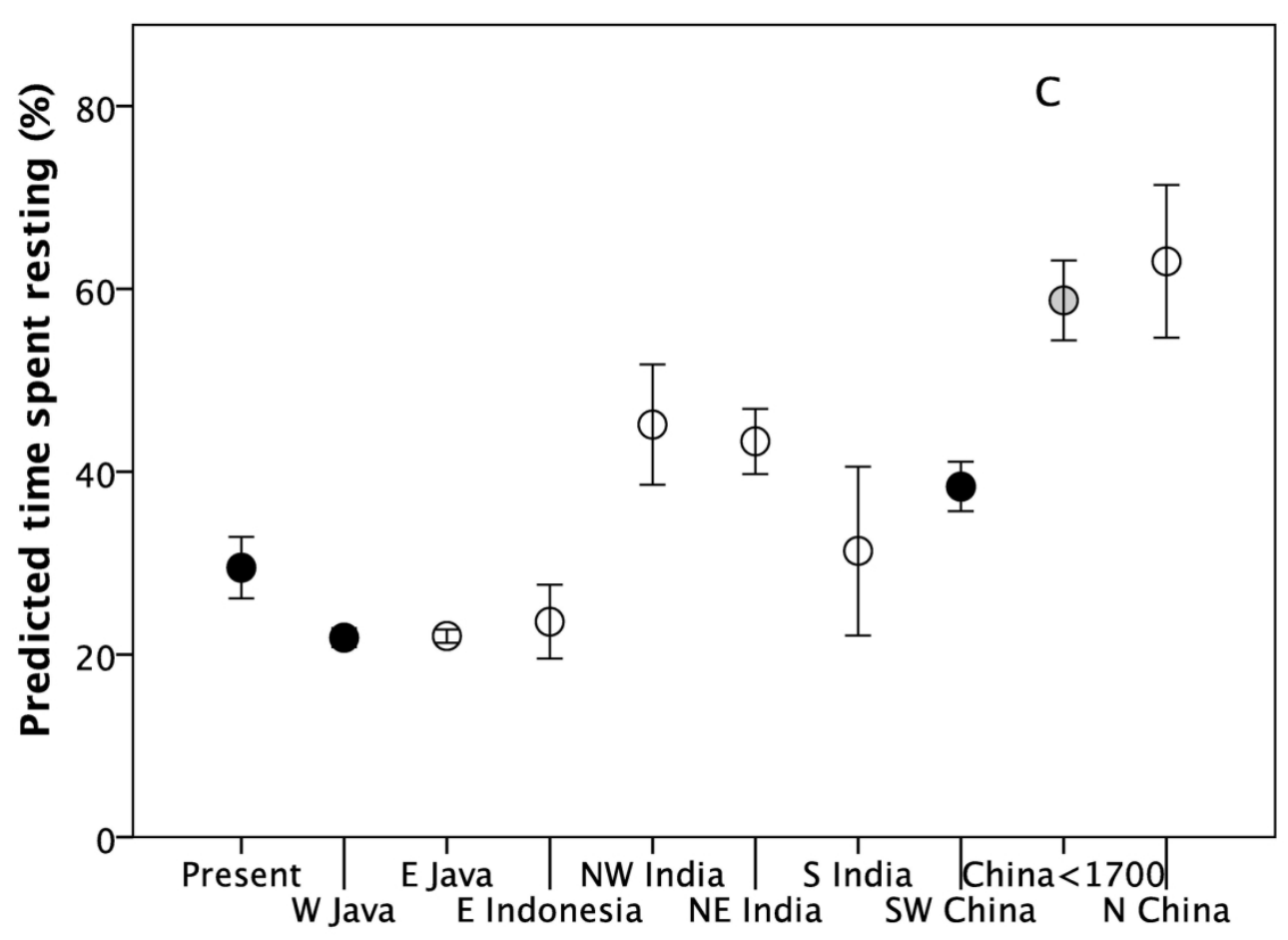

Fig. 6C

$165 \times 131 \mathrm{~mm}(300 \times 300 \mathrm{DPI})$ 


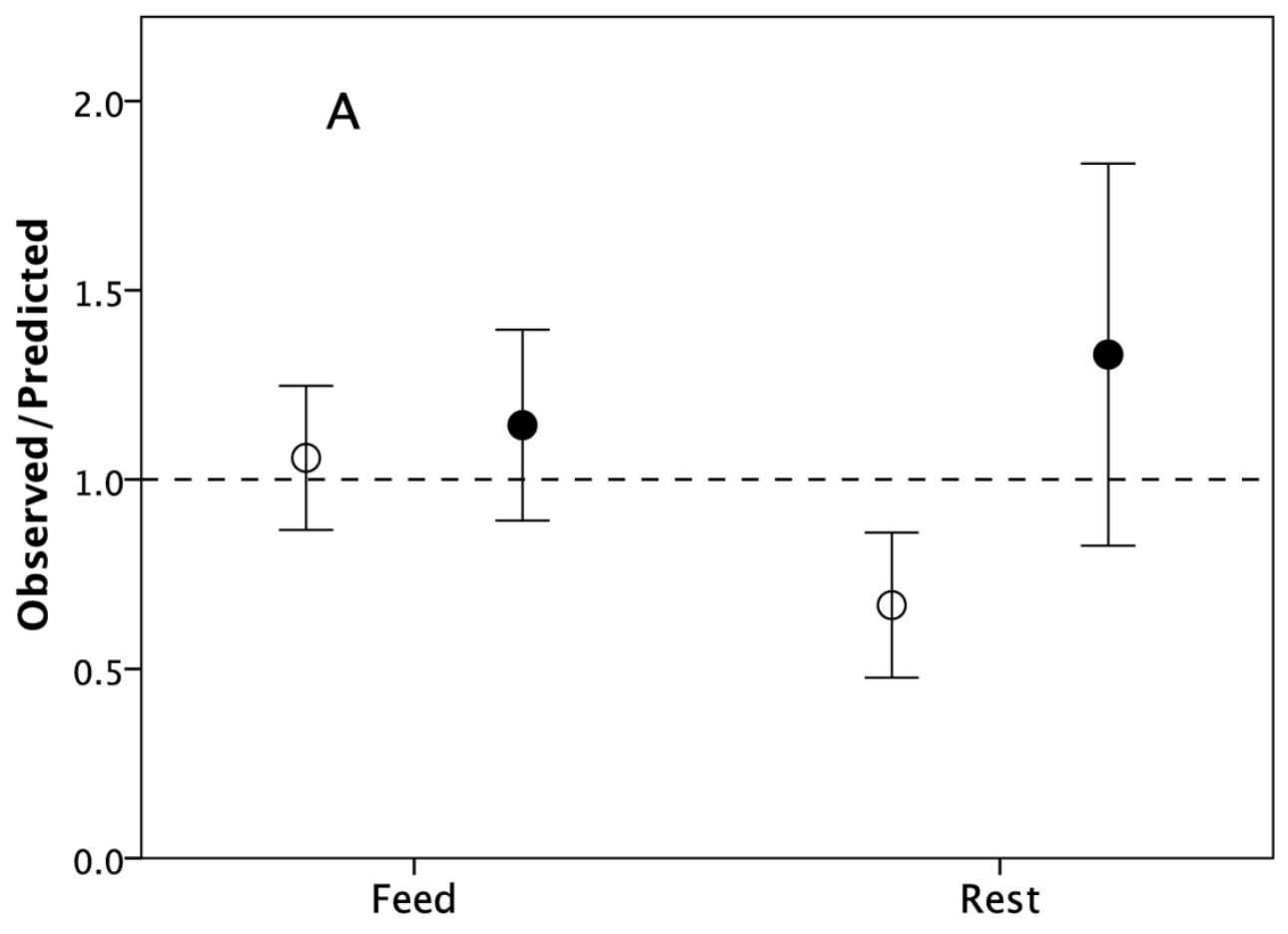

Fig. 7A

$165 \times 131 \mathrm{~mm}(300 \times 300$ DPI)

John Wiley \& Sons 


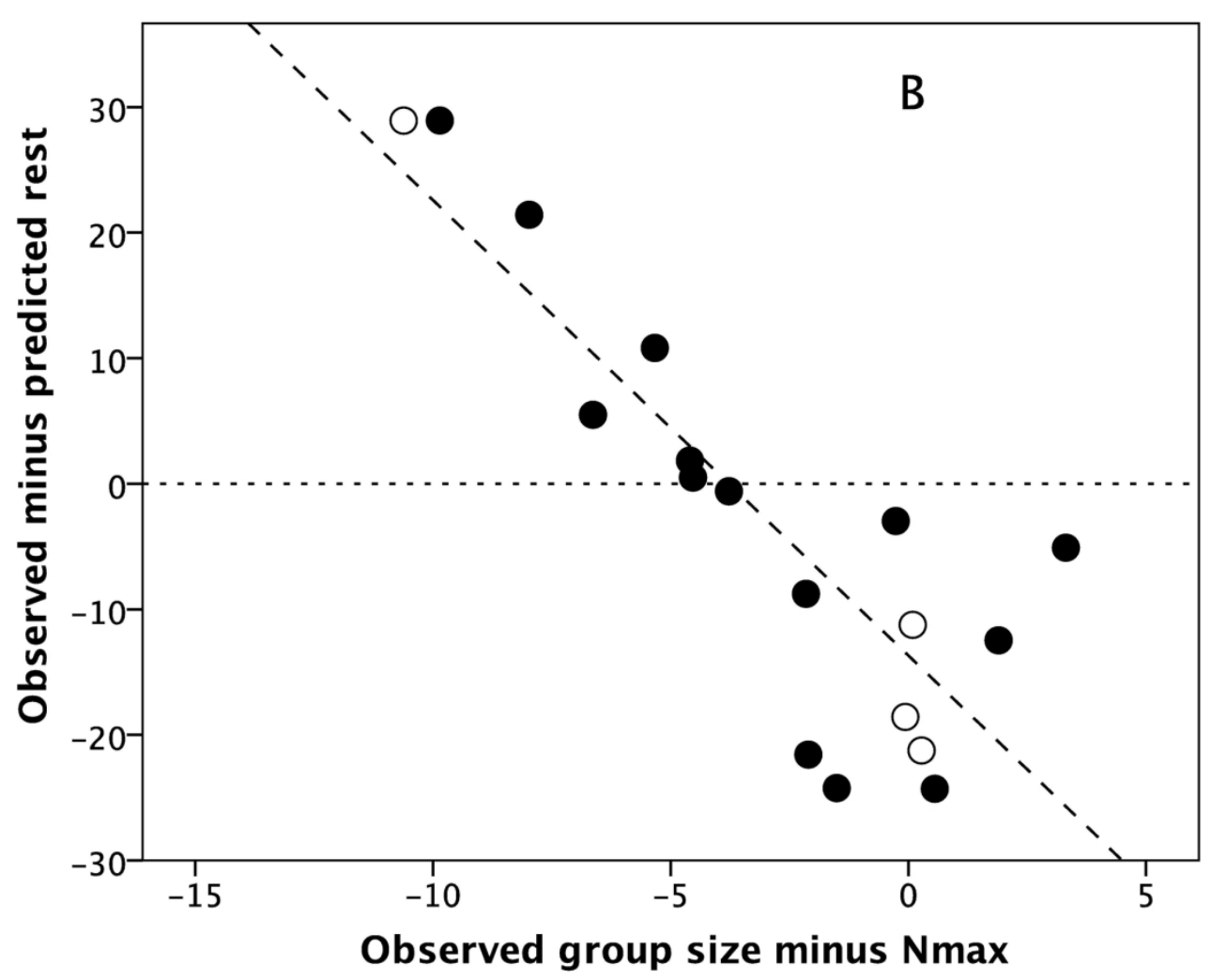

Fig. 7B

$165 \times 131 \mathrm{~mm}(300 \times 300 \mathrm{DPI})$ 


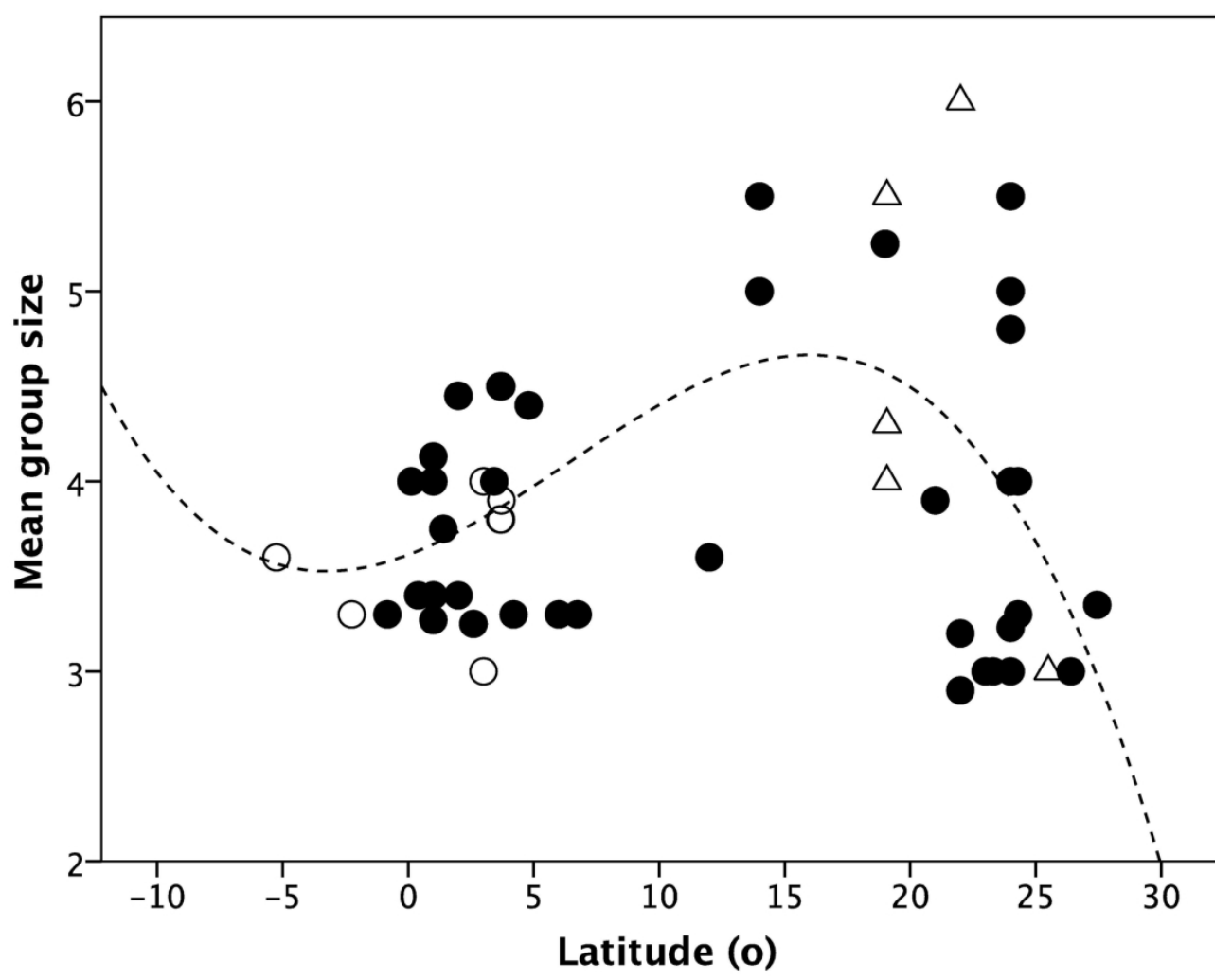

FIG. 8

$165 \times 131 \mathrm{~mm}(300 \times 300 \mathrm{DPI})$ 